\title{
Anais do I Congresso Mineiro: Abordagem Multidisciplinar da Morte Materno Infantil
}

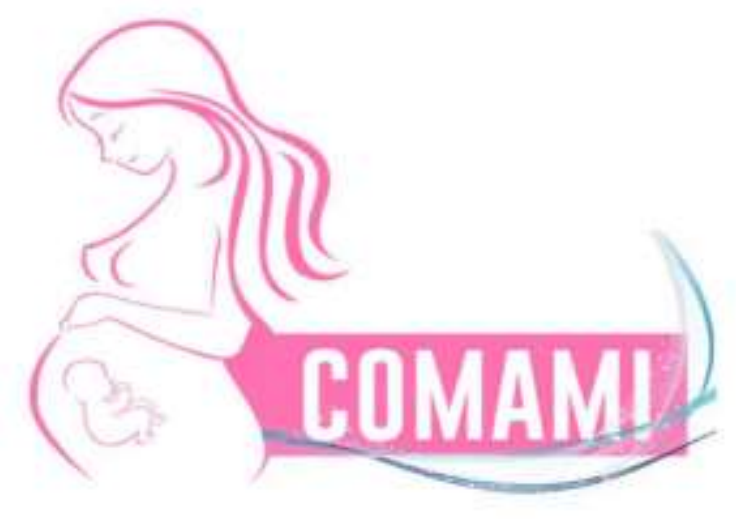

Apoio:

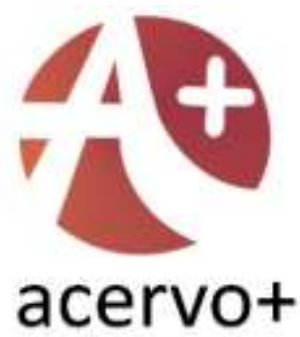

Eventos

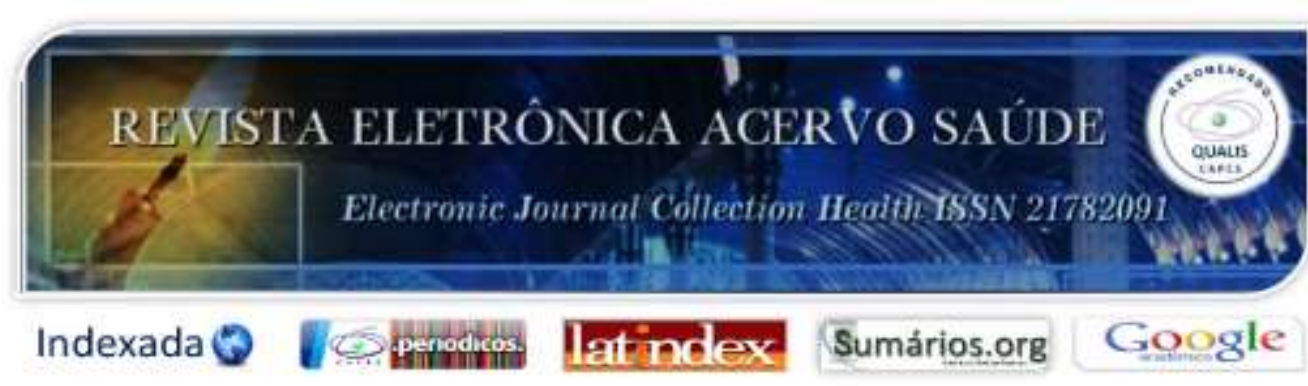




\section{SUMÁRIO}

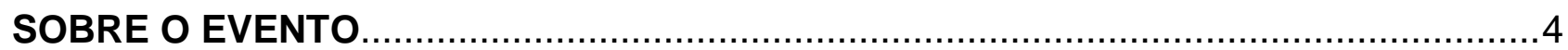

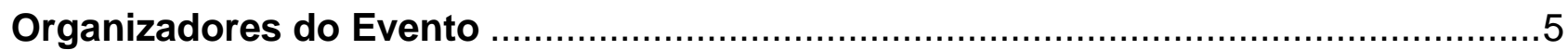

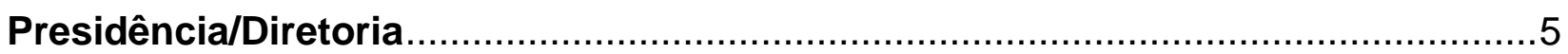

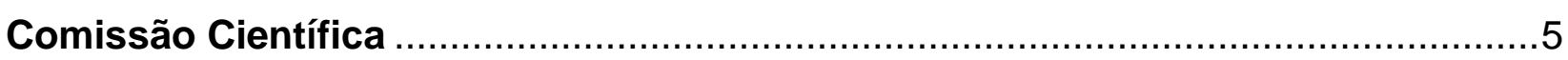

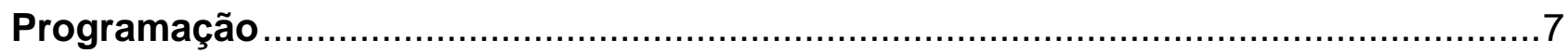

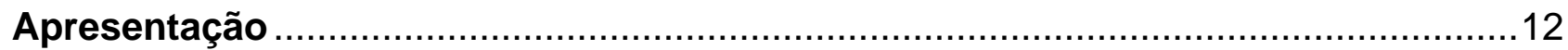

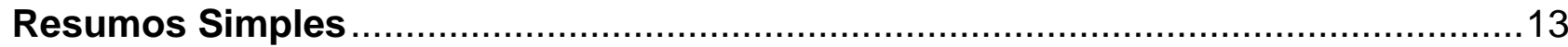

A endometriose como causa de infertilidade feminina: uma revisão bibliográfica.......13

A realização de histerectomia para tratamento de acretismo placentário ...................15

Atualizações sobre o rastreio do Diabetes Mellitus Gestacional (DMG) …................17

Avaliação do potencial terapêutico do Elagolix em mulheres com endometriose: uma

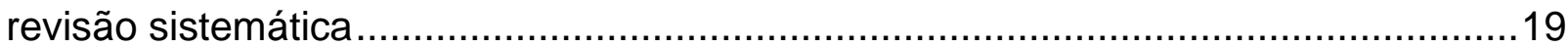

Cesárea Prévia: um fator de risco para complicações relacionadas à histerectomia..21 Como prevenir e conduzir a pré eclampsia, na Atenção Primária à Saúde, a fim de reduzir a mortalidade materna?.

Comparação da eficácia do mio-inositol e da metformina em pacientes com Síndrome dos Ovários Policísticos (SOP): uma revisão bibliográfica

Condicionantes e características da mortalidade materna no Brasil: uma revisão de literatura

Fatores associados ao excesso de cesárea no Brasil: uma revisão sistemática ........29

Fatores de risco para a Gravidez Ectópica: uma revisão sistemática da literatura .....31

Fatores que influenciam o impacto psicológico de parto de feto natimorto e morte neonatal nas gestantes

Importância da biópsia do linfonodo sentinela no prognóstico do paciente com câncer de mama: uma revisão bibliográfica

Importância do diagnóstico precoce da doença hipertensiva específica da gestação para o binômio mãe-feto 
Marcadores da reserva ovariana no contexto da reprodução assistida .39

Mecanismos de orte materna ocasionados pela pré-eclâmpsia. 41

Mulheres grávidas infectadas com covid-19: riscos aumentados? 43

O Cannabidio/ para manejo de dor em pacientes com endometriose .45

Pandemia covid 19 e o aumento da violência contra mulher .47

Redução do impacto psicológico para a gestante: feto natimorto e morte neonatal ...49 Repercussões vasculares na gestação de mulheres com anemia falciforme .51

Síndrome semelhante a pré-eclâmpsia induzida por Covid-19 grave: uma revisão da literatura .53

Uso de probióticos orais no tratamento e prevenção da recorrência de candidíase vulvovaginal: uma revisão sistemática .55 


\section{SOBRE O EVENTO}

O I Congresso Mineiro: abordagem multidisciplinar da morte materno infantil ocorrerá nos dias 8,9,10 de dezembro de 2020, das 18:00 às 21:00. Dada a situação de pandemia, o evento será online, por meio da plataforma "Stream Yard", de forma síncrona. O objetivo do Congresso é promover uma análise do impacto da mortalidade materna infantil em diversas áreas, como medicina, enfermagem, psicologia, direito, educação, economia, gestão, assistência social, política e fotografia. Além disso, partindo do pressuposto que a redução da morte materna infantil é um marcador de desenvolvimento humano e econômico para o país, sendo ainda a quarta meta do milênio, é de suma importância que se difunda e discuta sobre esse tema, baseando-se em informações de alta evidência científica. Foram convidados 24 palestrantes renomados, dentre eles existem membros da organização panamericana de saúde, diretores de sociedade mineira, diretores de hospitais municipais e regionais e diretores do comitê nacional de morte materna. Outrossim, buscamos atender um público amplo, desde estudantes até profissionais das áreas específicas supracitadas. Ademais, abrimos inscrições para submissão de trabalhos, sendo que eles serão apresentados de forma oral, assíncrona no evento. 


\section{Organizadores do Evento}

\section{Presidência/Diretoria}

Dr. Gabriel Costa Osanan

Dra. Elba Cristina Chaves

Dr. José Helvécio Kalil de Souza

Henrique Cássio Silva Rodrigues

Laryssa Vieira Gonçalves

Ana Luísa de Cássia Magalhães Ferreira

João Vitor Nunes Bastos Araújo

\section{Comissão Científica}

\section{Coordenador científico}

Tarsila de Paiva Ribeiro

\section{Integrantes da comissão científica}

Larissa de Oliveira Cassini Marques

Letícia Pereira Mendonça

Daniela Teixeira Ribeiro

\section{Integrantes da banca avaliadora \\ Dr. José Helvécio Kalil de Souza \\ Dr. Hugo Drumond Ribeiro \\ Dr. Eduardo Batista Cândido}

\section{Plataforma e Transmissão do Evento}

Lucas de Oliveira Santana

Isadora Barbosa de Deus

Hortência Angelina Silva Pinto 
Gustavo Lopes de Brito Costa

Luíza Passos Ribeiro

Financeiro

Júlia Marques Vieira

Juliana Vieira Queiroz Almeida

\section{Relações Externas}

Maria Elisa Nunes dos Santos Cortes

Marina Oliveira Quinto

João Marcelo Guimarães de Abreu

\section{Marketing}

Gabriel Machado Azevedo de Freitas

Ana Beatriz Guimarães Custódio

Bruna Gonçalves Antunes

Henrique Figueiredo Silva

Karla Cândia Parreira 


\section{Programação}

\begin{tabular}{|c|c|c|c|c|}
\hline \multicolumn{5}{|c|}{ Dia $1-08 / 12 / 2020$} \\
\hline Horário & \multicolumn{4}{|c|}{$\begin{array}{l}\text { I Congresso Mineiro: Abordagem Multidisciplinar da Morte Materno } \\
\qquad \text { Infantil }\end{array}$} \\
\hline $18: 00-18: 40$ & Palestra & $\begin{array}{c}\text { Situação atual da } \\
\text { Mortalidade Materno } \\
\text { Infantil }\end{array}$ & $\begin{array}{l}\text { Dra. Juliana Silva } \\
\qquad \text { Barra }\end{array}$ & Sala 1 \\
\hline $18: 40-19: 20$ & Palestra & $\begin{array}{l}\text { O pré-natal de risco } \\
\text { habitual: uma visão } \\
\text { sobre a evolução dos } \\
\text { cuidados maternos e } \\
\text { redução dos } \\
\text { desfechos negativos }\end{array}$ & $\begin{array}{l}\text { Dr. Oswaldo Prado } \\
\text { Cunha }\end{array}$ & Sala 1 \\
\hline $19: 20-20: 00$ & Palestra & $\begin{array}{l}\text { O pré-natal de alto } \\
\text { risco: contexto, } \\
\text { condutas e desafios }\end{array}$ & $\begin{array}{l}\text { Dr. Antônio Carlos } \\
\text { Vieira Cabral }\end{array}$ & Sala 1 \\
\hline $20: 00-20: 40$ & Palestra & "Near Miss" & $\begin{array}{l}\text { Dra. Fávia Vieira } \\
\text { Cordeiro Veloso }\end{array}$ & Sala 1 \\
\hline
\end{tabular}

\begin{tabular}{|c|c|c|c|c|}
\hline \multicolumn{5}{|c|}{ Dia $1-08 / 12 / 2020$} \\
\hline Horário & I Congresso & $\begin{array}{r}\text { eiro: Abordagem ML } \\
\text { Infant }\end{array}$ & Itidisciplinar da Mor & Materno \\
\hline $18: 00-18: 40$ & Palestra & $\begin{array}{l}\text { Mortalidade Materno } \\
\text { Infantil: um desafio } \\
\text { sem fronteiras }\end{array}$ & $\begin{array}{c}\text { Dra. Marcella Israel } \\
\text { Rocha }\end{array}$ & Sala 2 \\
\hline
\end{tabular}


Anais de Evento do I Congresso Mineiro: Abordagem Multidisciplinar da Morte Materno Infantil

\begin{tabular}{|c|c|c|c|c|}
\hline 18:40-19:20 & Palestra & $\begin{array}{c}\text { Síndrome } \\
\text { Hemorrágica na } \\
\text { gestação: uma } \\
\text { emergência obstétrica }\end{array}$ & $\begin{array}{c}\text { Dr. Gabriel Costa } \\
\text { Osanan }\end{array}$ & Sala 2 \\
\hline 19:20-20:00 & Palestra & $\begin{array}{c}\text { O papel da } \\
\text { enfermagem } \\
\text { obstétrica na redução } \\
\text { da Morte Materno- } \\
\text { infantil }\end{array}$ & $\begin{array}{c}\text { Snf. Elis Regina } \\
\text { Silva Pinheiro }\end{array}$ & Sala 2 \\
\hline 20:00-20:40 & Palestra & $\begin{array}{c}\text { Urgências e } \\
\text { emergência } \\
\text { hipertensivas na } \\
\text { gestação }\end{array}$ & Dr. Francisco Lírio \\
& & Ramos Filho & Sala 2 \\
\hline
\end{tabular}

\begin{tabular}{|c|c|c|c|c|}
\hline \multicolumn{5}{|c|}{ Dia $2-09 / 12 / 2020$} \\
\hline Horário & \multicolumn{4}{|c|}{$\begin{array}{l}\text { I Congresso Mineiro: Abordagem Multidisciplinar da Morte Materno } \\
\text { Infantil }\end{array}$} \\
\hline $18: 00-18: 40$ & Palestra & $\begin{array}{c}\text { Mortalidade materna } \\
\text { e infantil: da } \\
\text { codificação à seleção } \\
\text { das principais causas }\end{array}$ & $\begin{array}{c}\text { Dra. Regina Amélia } \\
\text { Lopes Pessoa de } \\
\text { Aguiar }\end{array}$ & Sala 1 \\
\hline $18: 40-19: 20$ & Palestra & $\begin{array}{c}\text { Prematuridade e } \\
\text { infecções congênitas } \\
\text { associado à Morte } \\
\text { Neonatal }\end{array}$ & $\begin{array}{c}\text { Dra. Thayse Izabela } \\
\text { Magalhães } \\
\text { Nogueira }\end{array}$ & Sala 1 \\
\hline
\end{tabular}


Anais de Evento do I Congresso Mineiro: Abordagem Multidisciplinar da Morte Materno Infantil

\begin{tabular}{|c|c|c|c|c|}
\hline 19:20-20:00 & Palestra & $\begin{array}{c}\text { Desmistificando e } \\
\text { assistência neonatal } \\
\text { no contexto da Morte } \\
\text { Materna }\end{array}$ & $\begin{array}{c}\text { Dra. Lorena Zuba } \\
\text { Santos }\end{array}$ & Sala 1 \\
\hline 20:00-20:40 & Palestra & $\begin{array}{c}\text { Covid-19 como causa } \\
\text { de morte neonatal } \\
\text { infantil: } \\
\text { enfrentamento, } \\
\text { desafios e } \\
\text { perspectivas }\end{array}$ & Dra. Maria Albertina \\
Santiago Rego & Sala 1 & \\
\hline
\end{tabular}

\begin{tabular}{|c|c|c|c|c|}
\hline \multicolumn{5}{|c|}{ Dia 2 - 09/12/2020 } \\
\hline Horário & I Congresso Mineiro: Abordagem Multidisciplinar da Morte Materno \\
Infantil & $\begin{array}{c}\text { Medicina baseada } \\
\text { em evidências e } \\
\text { respeito à autonomia } \\
\text { 18:00-18:40 gestante e } \\
\text { parturiente: } \\
\text { Prevenção aos } \\
\text { processos }\end{array}$ & $\begin{array}{c}\text { Kalil de Souza } \\
\text { Dr. José Helvécio }\end{array}$ & Sala 2 \\
\hline 18:40-19:20 & Palestra & $\begin{array}{c}\text { Judicialização da } \\
\text { Palestra }\end{array}$ & $\begin{array}{c}\text { Dra. Elba Cristina } \\
\text { Chaves }\end{array}$ & Sala 2 \\
\hline 19:20-20:00 & Palestra & $\begin{array}{c}\text { Impactos da Morte } \\
\text { Materna no Sistema } \\
\text { Educacional }\end{array}$ & $\begin{array}{c}\text { Prof. Robson } \\
\text { Gomes de Brito }\end{array}$ & Sala 2 \\
\hline
\end{tabular}




\begin{tabular}{|c|c|c|c|c|}
\hline $20: 00-20: 40$ & Palestra & $\begin{array}{l}\text { Mortalidade materno } \\
\text { infantil: mediação de } \\
\text { conflitos entre } \\
\text { instituições da saúde } \\
\text { e pacientes }\end{array}$ & $\begin{array}{c}\text { Dra. Luciana } \\
\text { Dadalto }\end{array}$ & Sala 2 \\
\hline
\end{tabular}

\begin{tabular}{|c|c|c|c|c|}
\hline \multicolumn{5}{|c|}{ Dia $3-10 / 12 / 2020$} \\
\hline Horário & \multicolumn{4}{|c|}{$\begin{array}{l}\text { I Congresso Mineiro: Abordagem Multidisciplinar da Morte Materno } \\
\qquad \text { Infantil }\end{array}$} \\
\hline $18: 00-18: 40$ & Palestra & $\begin{array}{c}\text { Um adeus } \\
\text { necessário: técnica } \\
\text { de enfrentamento ao } \\
\text { luto diante da perda } \\
\text { do filho }\end{array}$ & $\begin{array}{l}\text { Paula Beltrão } \\
\text { Viegas }\end{array}$ & Sala 1 \\
\hline $18: 40-19: 20$ & Palestra & $\begin{array}{c}\text { Depressão Peri-Parto } \\
\text { aspectos } \\
\text { negligenciados }\end{array}$ & $\begin{array}{l}\text { Dr. Humberto } \\
\text { Corrêa da Silva } \\
\text { Filho }\end{array}$ & Sala 1 \\
\hline $19: 20-20: 00$ & Palestra & $\begin{array}{l}\text { Manejo psicológico } \\
\text { no cenário de ruptura } \\
\text { do binômio mãe-filho }\end{array}$ & $\begin{array}{c}\text { Psic. Mythes Lanna } \\
\text { Mayrink e Castro }\end{array}$ & Sala 1 \\
\hline $20: 00-20: 40$ & Palestra & $\begin{array}{l}\text { Espiritualidade e luto: } \\
\text { aprendendo a perder } \\
\text { sem se perder }\end{array}$ & $\begin{array}{l}\text { Dra. Mônica Nardy } \\
\text { Lima }\end{array}$ & Sala 1 \\
\hline
\end{tabular}




\begin{tabular}{|c|c|c|c|c|}
\hline \multicolumn{5}{|c|}{ Dia $3-10 / 12 / 2020$} \\
\hline \multirow{2}{*}{$\begin{array}{c}\text { Horário } \\
\text { 18:00 - 18:40 }\end{array}$} & \multicolumn{4}{|c|}{$\begin{array}{l}\text { I Congresso Mineiro: Abordagem Multidisciplinar da Morte Materno } \\
\qquad \text { Infantil }\end{array}$} \\
\hline & Palestra & $\begin{array}{l}\text { Impacto da Morte } \\
\text { Materno Infantil na } \\
\text { economia brasileira }\end{array}$ & $\begin{array}{c}\text { Me. Jayne Cecília } \\
\text { Martins }\end{array}$ & Sala 2 \\
\hline $18: 40-19: 20$ & Palestra & $\begin{array}{l}\text { Gestão Hospitalar no } \\
\text { Contexto da } \\
\text { Mortalidade Materno } \\
\text { Infantil }\end{array}$ & $\begin{array}{c}\text { Dr. Marcelo Lopes } \\
\text { Ribeiro }\end{array}$ & Sala 2 \\
\hline $19: 20-20: 00$ & Palestra & $\begin{array}{l}\text { Políticas sociais na } \\
\text { prevenção da Morte } \\
\text { Materno Infantil }\end{array}$ & $\begin{array}{l}\text { Virgínia Maran } \\
\text { Sales Santos }\end{array}$ & Sala 2 \\
\hline $20: 00-20: 40$ & Palestra & $\begin{array}{c}\text { Políticas públicas } \\
\text { acerca da } \\
\text { mortalidade materna: } \\
\text { os desafios ao longo } \\
\text { da história }\end{array}$ & $\begin{array}{c}\text { Dra. Mônica } \\
\text { lassana dos Reis }\end{array}$ & Sala 2 \\
\hline
\end{tabular}




\section{Apresentação}

Prezados leitores, estes são os Anais do I Congresso Mineiro: Abordagem Multidisciplinar da Morte Materno Infantil - COMAMI, realizado entre os dias 8 e 10 de dezembro de 2020.

A Comissão Científica do I COMAMI em parceria com a Revista Eletrônica Acervo Saúde organizaram os Anais contendo os resumos aprovados, objetivando contemplar a complexidade e a diversidade de conteúdo dentro da área de Ginecologia e Obstetrícia. Foram 22 resumos aprovados, todos no formato de resumo simples. Nenhum trabalho realizou pesquisa com humanos ou animais. Os critérios de avaliação utilizados foram: seguir as regras de formatação e identificação expressas no edital do evento, possuir título conciso e informativo com precisão e fidedignidade textual, introdução que define e sintetiza o tema estudado por meio de citações indiretas atuais e confiáveis, sendo ela de fácil compreensão para leitores em geral, objetivo claro e pertinente à proposta do estudo, método que apresente de forma detalhada a fonte de dados, população, amostragem, critérios de seleção, procedimentos analíticos e questões éticas, resultados e discussão que responde à pergunta do estudo e atende o objetivo proposto, apresentando dados de forma didática e ilustrativa, possuir uma conclusão/considerações finais pertinente aos dados/resultados apresentados, possuir narrativa com fluidez e linguagem adequada, ser um conteúdo novo de interesse, com qualidade e originalidade e possuir aplicação, informação e/ou conhecimento no âmbito científico. 


\section{Resumos Simples}

RESUMO SIMPLES: Revisão Bibliográfica

Título: A endometriose como causa de infertilidade feminina: uma revisão bibliográfica

Autor/coautores: Polyana Fernandes Ruggio, Lívia Fernandes Monteiro da Mata, Natália Corrêa da Silva, Neoma Mendes de Assis.

Instituição: Faculdade de Minas - BH (Faminas - BH), Belo Horizonte - MG.

Palavras-chave: Endometriose, Infertilidade, Dor Pélvica

\section{INTRODUÇÃO}

A endometriose acomete cerca de $15 \%$ de mulheres em idade reprodutiva, sendo considerada a principal causa de infertilidade na mulher (DE SOUZA GKT, et al., 2017). Trata-se de uma patologia onde o tecido endometrial se localiza fora do útero, podendo acometer órgãos adjacentes como ovários, trompas, intestino, bexiga, peritônio, dentro outros. Os principais sinais e sintomas são a dor pélvica e irregularidades do ciclo menstrual. Dentre os tratamentos disponíveis estão o uso de hormônios e a excisão cirúrgica. O ideal é realizar o diagnóstico precoce para evitar a progressão da doença e suas possíveis complicações, sendo a principal delas a infertilidade (OLIVEIRA FS, et al., 2020).

\section{OBJETIVO}

Estudar por meio de revisão da literatura a endometriose, sua fisiopatologia, assim como as consequências para a mulher que a apresenta e principal complicação, a infertilidade, além de apresentar alternativas de tratamento.

\section{REVISÃO BIBLIOGRÁFICA}

A endometriose é uma patologia crônica e inflamatória definida pela presença de tecido endometrial localizado fora da cavidade uterina. Pode se instalar em diversos locais como ovários, trompas, intestino, bexiga, peritôneo, dentro outros. É conhecida como a doença da mulher moderna devido à prevalência nas mulheres com gravidez tardia, poucos filhos, menarca precoce e hábitos estressantes (DE SOUZA GKT, et al., 2017). Estima-se que $50 \%$ das mulheres com problemas de infertilidade tenham endometriose (DE SOUZA GKT, et al., 2017). É a principal causa de infertilidade na mulher, porque as aderências do tecido endometrial fora da cavidade uterina podem gerar ineficiência da ovulação e baixo índice de fertilização, alterações nas trompas, dificuldade da implantação do embrião no útero e dificuldade no transporte do óvulo pela tuba uterina (DE SOUZA GKT, et al., 2017). Um dos fatores mais preocupantes é a demora no diagnóstico. Mulheres acometidas pela endometriose podem optar por tratamento hormonal ou cirúrgico, que 
aumentam a chance de concepção futura (CACCIATORI FA, et al., 2016). Também podem optar por técnicas de reprodução assistida que também aumentam a chance de gravidez (DE SOUZA GKT, et al., 2017).

\section{CONSIDERAÇÕES FINAIS}

A relação da endometriose com a infertilidade é um fator preocupante, visto que muitas pacientes sonham com a maternidade e os custos elevados com técnicas de reprodução assistida podem ser um empecilho para tal. Dessa forma, é importante entender com clareza a relação entre endometriose e infertilidade e como os tratamentos empregados podem reverter ou minimizar os impactos da doença.

\section{REFERÊNCIAS}

1. CACCIATORI FA, et al. Endometriose: uma revisão da literatura. Revista de Iniciação Científica, 2016; 13(1): 56-66.

2. DE SOUZA GKT, et al. Endometriose $x$ infertilidade: revisão de literatura. Encontro de Extensão, Docência e Iniciação Científica (EEDIC), 2017; 3(1): sem paginação Web.

3. OLIVEIRA FDS, et al. Endometriose e gestação: existe impacto no desfecho gestacional? Revista de Patologia do Tocantins, 2020; 7(2): 26-30. 
RESUMO SIMPLES: Revisão Bibliográfica

Título: A realização de histerectomia para tratamento de acretismo placentário

Autor/coautores: Bruno Henrique Gonçalves Almada1; Juliana Vieira Queiroz Almeida²; Sarah Louredo Torquette'; Hugo Drumond Ribeiro².

Instituição: ${ }^{1}$ Faculdade de Ciências Médicas de Minas Gerais (FCMMG), Belo Horizonte - MG; ${ }^{2}$ Faculdade de Minas - Belo Horizonte (FAMINAS-BH), Belo Horizonte - MG.

Palavras-chave: Histerectomia; Acretismo placentário; Tratamento.

\section{INTRODUÇÃO}

O espectro da placenta acreta (PAS) apresenta morbidade de $24-67 \%$ e mortalidade materna e risco significativo de morte de 7\%, sendo a incidência de PAS estimada de 1 em 533 partos (ZUCKERWISE LC, et al., 2020). A PAS pode causar: hemorragia significativa com falência de sistemas, risco de transfusão, coagulopatia, lesão operatória, necessidade de cuidados intensivos e morte, sendo a histerectomia planejada capaz de evitar hemorragia maciça (SENTILHES L, et al., 2018). Há abordagens cirúrgicas conservadoras que geralmente são consideradas, pela literatura, como sob investigação (ZUCKERWISE LC, et al., 2020).

\section{OBJETIVO}

Averiguar se a histerectomia, considerada tratamento tradicional quando acretismo placentário, é um bom tratamento para a patologia e se existem outros métodos, consideradas eficazes, a serem avaliados e considerados como terapêuticos.

\section{MÉTODO}

Revisão integrativa com busca na plataforma Pubmed com descritores: "hysterectomy" e "placenta accreta". Foram analisados 468 artigos publicados nos 5 últimos anos, selecionando, 32 artigos pelo título, 13 pelo resumo e 6 pelo texto. Foram inclusos artigos que abordavam: histerectomia como tratamento de acretismo placentário, em inglês e francês. Exclui-se artigos com enfoque em técnicas cirúrgicas.

\section{REVISÃO BIBLIOGRÁFICA}

O diagnóstico adequado é relacionado a diminuição da morbidade, identificação dos riscos e possibilidade de escolha da técnica mais apropriada. $O$ tratamento conservador, apesar do risco de sangramento e infecção, evita a histerectomia em $80 \%$ dos casos, parecendo promissor (DANEY MF, et al., 2016). A abordagem extirpada, associada à histerectomia, deve ser realizada somente quando baixa probabilidade de PAS. Já a histerectomia planejada tardia, sem remoção placentária, causa desprendimento espontâneo da placenta, sendo considerada padrão-ouro (SENTILHES L, et al., 2018). O "American College of Obstetricians and Gynecologists" não recomenda a histerectomia como tratamento primário em jovens, hemodinamicamente estáveis com coagulação adequada e desejo de engravidar (BOBSOBSAI Y, et al., 2016) por impossibilitar a gestação, aumentar a perda sanguínea e complicações perioperatórios (CIRPAN T, et al., 2019). São desvantagens da histerectomia: sangramento pós procedimento relacionado a neovascularização, dano a órgãos adjacentes, perda da fertilidade com possíveis implicações psicológicas e cistotomia. O manejo depende do diagnóstico, experiência cirúrgica, recursos intervencionistas e transfusórios e desejo de gestação futura (PIÑAS CA e CHANDRAHARAN E, 2019). 


\section{CONSIDERAÇÕES FINAIS}

O manejo é relacionado ao diagnóstico pré-natal. Ademais, o tratamento conservador parece ter melhores resultados, apesar de ser relatado complicações incertas. Sendo assim, necessita-se de mais estudos para averiguar se ele é o padrão-ouro em determinadas situações e qual a gestão cirúrgica mais segura.

\section{REFERÊNCIAS}

1. SENTILHES L, et al. Conservative Management of Placenta Accreta Spectrum. Clin Obstet Gynecol. 2018; 61(4):783-794.

2. CIRPAN T, et al. Effectiveness of segmental resection technique in the treatment of placenta accreta spectrum. J Matern Fetal Neonatal Med. 2019; 12: 1-7.

3. BAI Y, et al. High-intensity focused ultrasound treatment of placenta accreta after vaginal delivery: a preliminary study. Ultrasound Obstet Gynecol. 2016; 47(4): 492-8.

4. DANEY MF, et al. Morbimortalité maternelle associée au traitement conservateur d'un placenta anormalement adhérent (accreta) diagnostiqué en anténatal. À propos d'une série continue de 15 cas [Maternal morbidity and mortality associated with conservative management for placenta morbidly adherent (accreta) diagnosed during pregnancy. Report of 15 cases]. J Gynecol Obstet Biol Reprod (Paris). 2016; 45(8): 849-858.

5. CARRILLO AP, CHANDRAHARAN E. Placenta accreta spectrum: Risk factors, diagnosis and management with special reference to the triple $P$ procedure. Womens Health (Lond). 2019 Jan-Dec; 15:1745506519878081.

6. ZUCKERWISE LC, et al. Outcomes following a clinical algorithm allowing for delayed hysterectomy in the management of severe placenta accreta spectrum. Am J Obstet Gynecol. 2020; 222(2): 179. e1-179.e9. 
RESUMO SIMPLES: Revisão Bibliográfica

Título: Atualizações sobre o rastreio do Diabetes Mellitus Gestacional (DMG)

Autor/coautores: Izadora Marina de Oliveira Sabino1/Bárbara Domingues da Silva'; joão Pedro Soares Rodrigues ${ }^{1}$; Ádria Camila Silva²; Rayana Rolla Campos³.

Instituição: Faculdade de Minas de Belo Horizonte (FAMINAS-BH), Belo Horizonte - MG'; Centro Universitário UNIFAMINAS, Muriaé - MG²; Universidade Federal de Minas Gerais (UFMG), Belo Horizonte $M^{3}$.

Palavras-chave: Diabetes mellitus gestacional, Rastreio, Pré-natal.

\section{INTRODUÇÃO}

O diabetes mellitus gestacional (DMG) é uma complicação grave da gravidez em que mulheres previamente hígidas desenvolvem hiperglicemia durante a gestação (PLOWS JF, et al., 2018). Está associado a risco aumentado de parto prematuro, pré-eclâmpsia, parto cirúrgico, desenvolvimento de doenças cardiovasculares e diabetes mellitus tipo 2 (DM2) tardiamente em mães e crianças (DICKENS LT e THOMAS $C C, 2019)$. Diversas estratégias envolvem o rastreio do DMG, não havendo consenso entre as sociedades obstétricas mundiais. Sendo assim, constitui problema de saúde pública, cujo estratégias de rastreio devem estar sempre atualizadas (KAUTZKY-WILLER A, et al., 2019).

\section{OBJETIVO}

Revisar a literatura científica a respeito do rastreio do DMG, valorizando as principais diretrizes validadas para o assunto e identificar a melhor metodologia de rastreio a ser aplicada no serviço de saúde brasileiro.

\section{MÉTODO}

Trata-se de uma revisão integrativa, utilizando os descritores "diabetes mellitus e gestação OU diabetes gestacional" em inglês, na base de dados Pubmed, entre 07/10/2020 e 15/10/2020. Foram encontrados 6.175 artigos, selecionando 4 destes. Foram incluídos artigos dos últimos 2 anos, e aqueles que não abordaram o rastreio do DMG foram excluídos. Ademais, foi utilizado o Tratado de Obstetrícia da Federação Brasileira das Associações de Ginecologia e Obstetrícia (FEBRASGO) de 2019.

\section{REVISÃO BIBLIOGRÁFICA}

No Brasil, os critérios diagnósticos levam em consideração a viabilidade financeira e a disponibilidade técnica dos serviços. Assim, até a vigésima semana de idade gestacional (IG) há 3 possibilidades diagnósticas: 1) glicemia de jejum (GJ) $\geq 126 \mathrm{mg} / \mathrm{dL}$ considera-se diabetes mellitus prévio; 2) $\mathrm{GJ} \geq 92 \mathrm{mg} / \mathrm{dL}$ diagnóstico de DMG; 3) valores < $92 \mathrm{mg} / \mathrm{dL}$ são considerados adequados para o início da gestação, sendo necessária nova investigação laboratorial entre 24 e 28 semanas, com o teste de tolerância oral a $75 \mathrm{~g}$ de glicose (TOTG $75 \mathrm{~g}$ ), avaliando os valores glicêmicos uma e duas horas após a ingestão do dextrosol. Os resultados para DMG utilizando o TOTG são: jejum $\geq 92, \geq 180 \mathrm{mg} / \mathrm{dL}$ na $1^{\circ}$ hora ou $\geq 153 \mathrm{mg} / \mathrm{dL}$ na $2^{\circ}$ hora. Uma das três dosagens alterada já confere o diagnóstico de DMG (BRASIL, 2019). Terapia nutricional e atividade física constituem proposta conservadora, sendo a insulina o tratamento farmacológico de escolha, caso necessário (SZMUILOWICZ ED, et al., 2019). 


\section{CONSIDERAÇÕES FINAIS}

Diante do exposto, é imprescindível que os atuantes no pré-natal tenham conhecimento atualizado sobre o rastreio e abordagem do DMG, objetivando diagnóstico precoce, propedêutica individualizada, obtenção de desenvolvimento fetal adequado e redução das taxas de mortalidade e comorbidades futuras.

\section{REFERÊNCIAS}

1. DICKENS LT, THOMAS CC. Updates in Gestational Diabetes Prevalence, Treatment, and Health Policy. Current Diabetes Reports, 2019; 19: 33.

2. KAUTZKY-WILLER A, et al. Gestational diabetes mellitus (Update 2019). Wien Klin Wochenschr, 2019; 131: 91-102.

3. PLOWS JF, et al. The Pathophysiology of Gestational Diabetes Mellitus. International Journal of Molecular Sciences, 2018; 19: 3342.

4. SZMUILOWICZ ED, et al. Gestational Diabetes Mellitus. Endocrinol Metab Clin North Am, 2019; 48: 479493.

5. BRASIL. Tratado de Obstetrícia da Federação Brasileira das Associações de Ginecologia e Obstetrícia. Editores Cesar Eduardo Fernandes, Marcos Felipe Silva de Sá; coordenação: Corintio Mariani Neto. - 1. ed. - Rio de Janeiro: Elsevier, 2019. 
RESUMO SIMPLES: Revisão Bibliográfica

Título: Avaliação do potencial terapêutico do Elagolix em mulheres com endometriose: uma revisão sistemática

Autor/coautor: Samuel Oliveira Dumont Horta, Camila Vieira Rocha de Sousa, Mariana Melo Morais, Michael Zarnowski Passos.

Instituição: Faculdade de Minas (FAMINAS-BH), Belo Horizonte - MG.

Palavras-chaves: Endometriosis, Elagolix, Treatment.

\section{INTRODUÇÃO}

A endometriose é uma doença inflamatória crônica, caracterizada pela presença de tecido endometrial ectópico afetando $6 \%$ a $10 \%$ das mulheres na idade reprodutiva. Os sintomas incluem disminorreia, dor pélvica não menstrual, dispauremia, dificuldade na defecação e micção (SURREY ES, et al., 2019). Isso pode afetar as atividades diárias, relações intimas e contato social (POKRZYWINSKI RM, et al., 2019). O Elagolix é um antagonista de $\mathrm{GnRH}$ que vem sendo estudado como alternativa para o tratamento da endometriose, visto que os tratamentos convencionais apresentam efeitos colaterais como perda óssea intensa e sintomas vasomotores graves.

\section{OBJETIVO}

Revisar por meio de uma revisão sistemática o potencial terapêutico do Elagolix em mulheres com endometriose, abordando a sua eficácia terapêutica, segurança para o seu uso e dosagem mais efetiva.

\section{METODOLOGIA}

Foi realizado uma revisão sistemática por meio de ensaios clínicos controlados randomizados, publicados em inglês, dos últimos cinco anos, em humanos, com referência ao MedLine. Os descritores foram traçados mediante consulta ao MeSH. Foram encontrados 40 estudos e após aplicação dos critérios de inclusão (diagnostico cirúrgico de endometriose), exclusão (dor crônica não relacionada a endometriose), 4 artigos foram selecionados. A escala PRISMA foi utilizada para melhorar o relato desta revisão.

\section{REVISÃO BIBLIOGRÁFICA}

O Elagolix teve uma resposta terapêutica efetiva e segura em mulheres com endometriose nos estudos analisados. Dois estudos demonstraram que as pacientes do grupo controle com dosagens de $200 \mathrm{mg}$ e $150 \mathrm{mg}$, comparada ao grupo placebo, tiveram resultados favoráveis com redução da disminorreia $(75,8 \%$; 78\%), dor pélvica não menstrual (54,5\%; 67\%) e dispareumia (60\%) (TAYLOR HS, et al., 2017) ( SURREY E, et al., 2018). Outros dois estudos demonstram que houve melhora significativa na qualidade de vida das pacientes. $43 \%$ das mulheres com dor moderada a grave tiveram redução dos níveis de fadiga (SURREY ES, et al.2019). Ademais, houve redução do absenteísmo com acréscimo de 4 horas de trabalhado e maior produtividade (POKRZYWINSKI RM, et al., 2019). Todos os estudos relataram que a população controle não teve problemas com o uso do medicamento de médio ( 6 meses) a longo prazo (12 meses), apesar dos efeitos adversos pela redução acentuada do estrógeno.

\section{CONSIDERAÇÕES FINAIS}

O Elagolix demostrou uma eficácia terapêutica significativa em mulheres com endometriose quanto dor pélvica não menstrual, disminorreia, dispareumia e qualidade de vida, além de ser segura. Todavia, efeitos 
adversos hipoestrogênicos como alteração do perfil lipídico e redução da densidade óssea foram observados. Nesse contexto, mais estudos são necessários para demonstrar qual a população é apropriada para esse tratamento.

\section{REFERÊNCIAS}

1. SURREY ES, et al. Impact of elagolix treatment on fatigue experienced by women with moderate to severe pain associated with endometriosis. Fertil Steril. 2019; 112(2): 298-304. e3.

2. SURREY E, et al. Long-Term Outcomes of Elagolix in Women With Endometriosis: Results From Two Extension Studies. Obstet Gynecol. 2018; 132(1): 147-160.

3. POKRZYWINSKI RM, et al. Impact of elagolix on work loss due to endometriosis-associated pain: estimates based on the results of two phase III clinical trials. Fertil Steril. 2019; 112(3): 545-551.

4. TAYLOR HS, et al. Treatment of Endometriosis-Associated Pain with Elagolix, an Oral GnRH Antagonist. N Engl J Med. 2017; 6, 377(1): 28-40. 
RESUMO SIMPLES: Revisão Bibliográfica

Título: Cesárea Prévia: um fator de risco para complicações relacionadas à histerectomia

Autor/coautores: Sarah Louredo Torquette'; Juliana Vieira Queiroz Almeida²; Bruno Henrique Gonçalves Almada'; Hugo Drumond Ribeiro²; José Helvécio Kalil de Souza².

Instituição: ${ }^{1}$ Faculdade de Ciências Médicas de Minas Gerais (FCMMG), Belo Horizonte - MG; ${ }^{2}$ Faculdade de Minas - Belo Horizonte (FAMINAS-BH), Belo Horizonte - MG.

Palavras-chave: Cesárea; Histerectomia; Fator de Risco.

\section{INTRODUÇÃO}

Segundo a OMS (2014) as taxas de cesárea ultrapassam 30\% na maioria dos países e, como o útero cicatrizado está sujeito a alterações funcionais, há maior predisposição a placentação anormal e hemorragia pós-parto, fatores de risco para a Histerectomia Obstétrica $(\mathrm{HO})$, nas mulheres que realizaram o procedimento. Ademais, há resultados adversos maternos, frequentemente consequentes a cesárea, que podem resultar em histerectomia, como: acretismo placentário e placenta prévia, que podem cursar com hemorragias, além das aderências abdominais entre os tecidos que envolvem o sítio cirúrgico da cesárea e lesões de órgãos adjacentes ao útero, como bexiga e intestino (SIMSEK D, et al., 2020).

\section{OBJETIVO}

Averiguar os resultados adversos da cesárea encontrados ao se realizar uma histerectomia, que podem ser relacionados à cesárea prévia e se foi relatado aumento da morbidade da mulher associado a eles.

\section{MÉTODO}

Revisão Integrativa com busca na plataforma Pubmed com descritores: cesárea e histerectomia. Foram analisados 976 artigos dos últimos 5 anos, sendo selecionados, pelo título, 47 artigos, pelo resumo, 11 e, pelo texto, 5. Incluiu-se artigos que abordavam: implicações da cesárea na histerectomia, em língua inglesa e portuguesa. Exclui-se artigos que os desfechos poderiam ter outras causas.

\section{REVISÃO BIBLIOGRÁFICA}

A cesárea pode implicar em $\mathrm{HO}$ ao favorecer a placentação anormal, com Odds Ratio (OR) de 3.2 para histerectomia comparada a atonia uterina (HUGUE S, et al., 2018), havendo aumento de complicações conforme o número de cesáreas (SIMSEK D, et al., 2020). Adesões abdominais entre a bexiga, trato urinário e parede abdominal são implicadores da histerectomia, comumente consequentes à cesárea (LIM S, et al., 2017). Até 2 cesáreas prévias há risco elevado de histerectomia e de lesão de órgãos durante o procedimento. Acima de 3, há risco elevado das condições citadas em 8 vezes, da necessidade de transfusão, se hemorragia, e de complicações de sítio cirúrgico. Observou-se aumento diretamente proporcional do número de cesáreas e morbidade materna (SONDGEROTH KE, et al., 2019). Uma meta-análise mostrou OR aumentado para lesão de trato urinário (3.15) e gastrointestinal (1.73), infeções pós-operatórias (1.44), complicações da ferida (2.24), necessidade de reoperação (1.46) e de transfusão sanguínea (1.35) (RATTANAKANOKCHAI S, et al., 2019).

\section{CONSIDERAÇÕES FINAIS}


A cesárea é um fator complicador e de risco para a histerectomia, por acarretar mudanças estruturais uterinas e de órgãos proximais, aumentando o risco cirúrgico da paciente, ocasionando impacto na morbidade dela. Entretanto, poucos artigos relacionavam a cesárea diretamente a necessidade de histerectomia e complicações durante o procedimento.

\section{REFERÊNCIAS}

1. HUQUE S, et al. Risk factors for peripartum hysterectomy among women with postpartum haemorrhage: analysis of data from the WOMAN trial. BMC Pregnancy Childbirth. 2018; 18(1): 186-186.

2. LIM S, et al. Safety of total laparoscopic hysterectomy in patients with prior cesarean section. J Obstet Gynaecol Res. 2017; 43(1):196-201.

3. RATTANAKANOKCHAI S, et al. Perioperative Complications of Hysterectomy After a Previous Cesarean Section: A Systematic Review and Meta-Analysis. Clin Epidemiol. 2019; 11: 1089-1098.

4. SIMSEK D, et al. Determinants of cesarean-related complications: high number of repeat cesarean, operation type or placental pathologies? J Matern Fetal Neonatal Med. 2020; 19: 1-7.

5. SONDGEROTH KE, et al. Risk of Maternal Morbidity with Increasing Number of Cesareans. Am J Perinatol. 2019; 36(4): 346-351. 
RESUMO SIMPLES: Revisão Bibliográfica

Título: Como prevenir e conduzir a pré eclampsia, na Atenção Primária à Saúde, a fim de reduzir a mortalidade materna?

Autor/coautores: Livia Moreira Campos ${ }^{1}$; Luciana Auad Guimarães²; Marina Fernandes Martins³; Laudislena Colodetti ${ }^{4}$

Instituição: Universidade José do Rosário Vellano $\mathrm{BH}^{1,2,3,4}$; Belo Horizonte - $\mathrm{MG}^{1}$; Belo Horizonte - $\mathrm{MG}^{2}$; Alfenas - MG33; Belo Horizonte - MG ${ }^{4}$.

Palavras-chave: Pré-eclâmpsia, Atenção primária à saúde, Mortalidade materna.

\section{INTRODUÇÃO}

A mortalidade materna representa importante realidade no mundo, por isso, com o intuito de reduzir a incidência dessa fatalidade, foram adotadas estratégias e realizadas conferências durante o tempo. (RESENDE LV, et al., 2015) O Brasil não atingiu sua meta - razão de mortalidade materna igual ou inferior a 35 mortes por 100000 nascidos vivos em 2015 - sendo assim necessária maior atenção quanto à conduta durante $o$ atendimento das gestantes (RESENDE LV, et al., 2015). As síndromes hipertensivas gestacionais (SHG), sendo a pré-eclâmpsia (PE) a mais comum e com piores desfechos maternos, no Brasil, estando presentes em 6 a 30\% das gestantes (CHISHOLM A, et al., 2016) (BRASIL, 2017).

\section{OBJETIVO}

Analisar o papel da Atenção Primária à Saúde na prevenção e orientação a respeito das síndromes hipertensivas gestacionais, principalmente na pré eclampsia, com o objetivo de reduzir a mortalidade materna.

\section{REVISÃO BIBLIOGRÁFICA}

As SHG são caracterizadas por níveis pressóricos iguais ou acima de 140mmHg para sistólica e 90 para diastólica e apresenta como fatores de risco diabetes mellitus, a obesidade, a presença de hipertensão arterial sistêmica prévia e a gestação após os 30 anos de idade (BRASIL, 2017). Tendo em vista esses fatores, a tendência é que os casos de SHG aumentem se não forem adotadas, pelos profissionais de saúde, medidas preventivas dessa enfermidade (BRASIL, 2017) (KAHHALE S, et al., 2018). A PE é definida como hipertensão após 20 semanas de gestação, associada à proteinúria, com desaparecimento até 12 semanas pós-parto (CHISHOLM A, et al., 2016). Os serviços de atenção primária à saúde são essenciais no atendimento da mulher com PE, por meio da realização do pré-natal de alto risco, assim como, no acompanhamento da gestante, providenciando encadeamento dos níveis secundário e terciário de atenção à saúde para casos de pacientes que demandem atendimento especializado (CHISHOLM A, et al., 2016) (BRASIL, 2017).

\section{CONCLUSÃO}

É de suma importância, na atenção primária à saúde, a identificação de fatores de risco relacionados ao desenvolvimento de SHG, sobretudo de PE, para que se possa promover uma vigilância mais cuidadosa da gestante, incluindo um pré-natal bem direcionado, alcançando assim as metas mundiais de redução da mortalidade materna no Brasil.

\section{REFERÊNCIAS}


1. BRASIL. Federação Brasileira das Associações de Ginecologia e Obstetrícia (FEBRASGO). 2017. Disponível em: https://www.febrasgo.org.br/media/k2/attachments/12-PRE_ECLAyMPSIA.pdf. Acessado em: 16 de outubro de 2020.

2. CHISHOLM A, et al. Hypertensive disorders of pregnancy. Dynamed Plus. 2016. Disponível em: https://www.dynamed.com/condition/hypertensive-disorders-of-pregnancy. Acessado em: 15 de outubro de 2020.

3. KAHHALE S, et al. Pré-Eclampsia. Rev Med, 2018; 97(2): 226-34.

4. RESENDE LV, et al. Mortes maternas em Belo Horizonte, Brasil: percepções sobre qualidade da assistência e evitabilidade. Rev Panam Salud Publica, 2015; 37(4/5): 218-24. 
RESUMO SIMPLES: Revisão Bibliográfica

Título: Comparação da eficácia do mio-inositol e da metformina em pacientes com Síndrome dos Ovários Policísticos (SOP): uma revisão bibliográfica

Autor/coautores: Camila Vieira Rocha de Sousa; Samuel Oliveira Dumont Horta; Mariana Melo de Morais; Michael Zarnowski Passos.

Instituição: Faculdade de Minas (FAMINAS-BH), Belo Horizonte - MG.

Palavras-chave: Polycystic ovary syndrome, Metformin, Inositol.

\section{INTRODUÇÃO}

A Síndrome dos Ovários Policísticos (SOP) é um distúrbio hiperandrogênico e metabólico comum em mulheres na idade reprodutiva, caracterizada por anovulação, hirsutismo e disfunção menstrual. A maioria das pacientes com SOP são afetadas pela resistência à insulina e dislipidemia (FRUZZETTI F, et al., 2017). Mulheres com SOP sofrem de ansiedade, depressão e significativa redução da qualidade de vida. Recentemente, novos sensibilizadores de insulina contendo inositol e a metformina vem sendo estudados visando avaliar o controle glicêmico e perfis lipídicos para tratamento de pacientes com SOP (JAMILIAN $\mathrm{H}$, et al., 2018).

\section{OBJETIVO}

Comparar, por meio de uma revisão sistemática, os efeitos do mio-inositol e da metformina no tratamento das características clínicas e metabólicas de mulheres com a Síndrome dos Ovários Policísticos.

\section{MÉTODO}

Foi realizado uma revisão sistemática por meio de ensaios clínicos controlados e randomizados, publicados em inglês, nos últimos cinco anos, em humanos, com referência ao MedLine. Os descritores foram traçados mediante consulta ao MeSH. Foram encontrados 225 estudos e após aplicação dos critérios de inclusão (mulheres com SOP entre 18 e 40 anos), exclusão (fumantes, gestantes e pacientes com doenças metabólicas), 6 artigos foram selecionados. A escala PRISMA foi utilizada para melhorar relato dessa revisão.

\section{REVISÃO BIBLIOGRÁFICA}

Com base nos estudos analisados, sugere-se que a metformina e o mio-inositol são igualmente eficazes na melhora da redução do IMC $(p<0,01)$ (JAMILIAN M, et al., 2017). Com relação à melhora do ciclo menstrual em pacientes com SOP, não foram observadas diferenças significativas $(p<0,001)$ (AGRAWAL A, et al., 2019). Ainda, a suplementação de mio-inositol, por 12 semanas, teve efeitos favoráveis sobre os parâmetros da saúde mental $(p=0,01)$ e níveis plasmáticos de capacidade antioxidante total $(p<0,001)$. A suplementação de mio-inositol reduziu a glicose plasmática de jejum $(p=$ $0,001)$, níveis séricos de insulina $(p<0,001)$, triglicerídeos séricos $(p=0,003)$ e níveis de colesterol VLDL $(p=0,003)$ (SHOKRPOUR M, et al., 2019). Nenhum efeito colateral foi evidenciado no grupo com mioinositol. Entretanto, após administração de metformina, 10\% das pacientes apresentaram efeitos gastrointestinais (TAGLIAFERRI V, et al., 2017).

\section{CONSIDERAÇÕES FINAIS}


O uso de mio-inositol, em comparação com metformina, parece ter efeito benéfico nas condições clínicas e metabólicas da SOP. Entretanto, alguns estudos não demonstraram diferenças significativas entre esses dois medicamentos. Assim, estudos com maior duração e tamanho da amostra são necessários visando confirmar nossos achados.

\section{REFERÊNCIAS}

1. AGRAWAL A, et al. Comparison of metformin plus myoinositol vs metformin alone in PCOS women undergoing ovulation induction cycles: randomized controlled trial. Gynecol Endocrinol. 2019; 35(6): 511514.

2. JAMILIAN M, et al. Comparison of myo-inositol and metformin on clinical, metabolic and genetic parameters in polycystic ovary syndrome: A randomized controlled clinical trial. Clin Endocrinol (Oxf). 2017; 87(2): 194-200.

3. JAMILIAN $\mathrm{H}$, et al. Comparison of myo-inositol and metformin on mental health parameters and biomarkers of oxidative stress in women with polycystic ovary syndrome: a randomized, double-blind, placebo-controlled trial. J Psychosom Obstet Gynaecol. 2018; 39(4): 307-314.

4. SHOKRPOUR M, et al. Comparison of myo-inositol and metformin on glycemic control, lipid profiles, and gene expression related to insulin and lipid metabolism in women with polycystic ovary syndrome: a randomized controlled clinical trial. Gynecol Endocrinol. 2019; 35(5): 406-411.

5. TAGLIAFERRI V, et al. Metformin vs myoinositol: which is better in obese polycystic ovary syndrome patients? A randomized controlled crossover study. Clin Endocrinol (Oxf). 2017; 86(5): 725-730.

6. FRUZZETTI F, et al. Comparison of two insulin sensitizers, metformin and myo-inositol, in women with polycystic ovary syndrome (PCOS). Gynecol Endocrinol. 2017; 33(1): 39-42. 
RESUMO SIMPLES: Revisão Bibliográfica

Título: Condicionantes e características da mortalidade materna no Brasil: uma revisão de literatura

Autor/coautores: João Vitor Borges Barbosa1, Michael Zarnowski Passos', Diogo Bohon Riskalla1, Matheus Serapião Teodoro', Mirelle Caroline De Souza'1.

Instituição: ${ }^{1}$ Faculdade de Minas - BH (FAMINAS-BH), Belo Horizonte - MG.

Palavras-chave: Mortalidade materna, Taxa de mortalidade, Revisão.

\section{INTRODUÇÃO}

A mortalidade materna (MM) é, além de um importante tópico da saúde pública, um bom marcador do desenvolvimento de um país, capaz de denunciar desigualdades sociais, problemas socioeconômicos e falta de assistência em saúde (SCARTON J, et al., 2019). Apesar dos esforços, o Brasil falha no que tange ao combate a MM, pois mantém parâmetros superiores aos propostos pela Organização Mundial da Saúde (OMS). Portanto, faz-se visível a necessidade de políticas públicas de cunho social, que ampliem o acesso à saúde e promovam melhorias na qualidade dos serviços ofertados, diminuindo o abismo socioeconômico, a fim de que os índices de MM sejam reduzidos (MARTINS ACS e SILVA LS, 2018).

\section{OBJETIVO}

Revisar a literatura atual, com o intuito de elucidar os motivos que acarretam a mortalidade materna, averiguar a posição, em relação ao mundo, ocupada pelo Brasil, possibilitando, portanto, a identificação de erros e a discussão das possíveis correções dentro do panorama vigente.

\section{REVISÃO BIBLIOGRÁFICA}

Ainda que, entre 1990 e 2008, o Brasil tenha reduzido à metade o índice de mortalidade materna (MM), para cerca de 60 mortes por 100.000 nascidos vivos (NV), esse indicador permanece aquém do limite de 20 mortes por 100.000 NV considerado razoável pela Organização Mundial da Saúde (OMS) (SCARTON J, et al., 2019). As taxas de mortalidade materna são superiores nos países em desenvolvimento e menores nos desenvolvidos, tornando-se um indicador das discrepâncias na qualidade da saúde (SCARTON J, et al., 2019). Mulheres negras, solteiras e as com baixa escolaridade representam segmentos associados a incidência aumentada de MM (MARTINS ACS e SILVA LS, 2018), assim como multíparas, mulheres com idade mais avançada e as submetidas a parto cesáreo (CARVALHO PI, et al., 2020). A população indígena apresenta o dobro da incidência de MM das demais (SANTOS DR, et al., 2017). As principais causas de MM são as hipertensivas, hemorrágicas e infecciosas, respectivamente, e os óbitos ocorrem sobretudo no puerpério (CARVALHO PI, et al., 2020). Abortos inseguros causam cerca de $15 \%$ das mortes maternas (RUAS CAM, et al., 2020).

\section{CONSIDERAÇÕES FINAIS}

É necessário adotar estratégias que visem a redução da MM no país, como medidas de diagnóstico precoce, planejamento familiar, melhoria da assistência pré-natal, parto e puerpério e ampliação destes serviços, sendo essencial aperfeiçoar o sistema de informação vigente, combatendo a subnotificação. Por último, os profissionais devem ser orientados quanto às medidas assistenciais, para que evitem possíveis complicações e adotem uma abordagem diligente, quando impreterível. 


\section{REFERÊNCIAS}

1. CARVALHO PI, et al. Perfil sociodemográfico e assistencial da morte materna em Recife, 2006-2017: estudo descritivo. Revista Epidemiologia e Serviços de Saúde, 2020; 29(1): e2019185.

2. MARTINS ACS, SILVA LS. Perfil epidemiológico de mortalidade materna. Revista Brasileira de Enfermagem, 2018; 71(supl1): 725-31.

3. RUAS CAM, et al. Perfil e distribuição espacial da mortalidade materna. Revista Brasileira de Saúde Materno Infantil, 2020; 20(2): 397-409.

4. SANTOS DR, et al. Mortalidade materna na população indígena e não indígena no Pará: contribuição para a vigilância de óbitos. Escola Anna Nery Revista de Enfermagem, 2017; 21(4): e20170161

5. SCARTON J, et al. Perfil da Mortalidade Materna: Uma Revisão Integrativa da Literatura. Journal of Research: Fundamental Care, 2019; 11(3): 816-822. 
RESUMO SIMPLES: Revisão Bibliográfica

Título: Fatores associados ao excesso de cesárea no Brasil: uma revisão sistemática

Autor/coautores: Livia Rocha Bridi'; Giovanna Aparecida da Silva² ${ }^{2}$ Éder Júlio Rocha de Almeida².

Instituição: ${ }^{1}$ Faculdade de Minas (FAMINAS), Belo Horizonte - MG; ${ }^{2}$ Universidade Vale do Rio Verde (UninCor), Betim - MG.

Palavras-chave: Cesárea, Obstetrícia, Perinatal.

\section{INTRODUÇÃO}

A partir do século $X X$ a cesariana foi considerada o procedimento cirúrgico mais realizado no mundo, sendo o Brasil o segundo país mais atuante (ZANARDO G, et al., 2017). A taxa de cesárea no Sistema Único de Saúde (SUS) é em torno de $41 \%$, e nas Instituições Privadas é de $88 \%$, muito além dos níveis recomendado pela comunidade médica Internacional, que estão entre 10\% a 15\% (OMS, 2015). Estudos recentes mostram que não há efetividade no excesso de realização de cesáreas desnecessárias, por não representarem benefício materno e fetal significativo (MASCARELLO K, et al., 2018).

\section{OBJETIVO}

Revisar a literatura cientifica abordando os principais fatores associados ao excesso de Cesárea no Brasil e relatar as possíveis complicações precoces e tardias que essa prática cirúrgica proporciona as gestantes.

\section{MÉTODO}

A revisão sistemática foi realizada em outubro de 2020 na plataforma da Biblioteca Virtual em Saúde (BVS) com as palavras-chaves "Cesárea", "Obstetrícia" e "Perinatal" verificadas nos Descritores em Ciências da Saúde (DeCS). Foram encontrados 46.934 artigos dos últimos 5 anos selecionado Cesárea; Cuidado PréNatal; Sistema Único de Saúde; Brasil com idiomas em Português e Espanhol. Houve a exclusão de artigos com ausência de dados a serem extraídos, totalizando 28 artigos e selecionando 4 juntamente a Declaração da Organização Mundial da Saúde (OMS) sobre as Taxas de Cesárea.

\section{REVISÃO BIBLIOGRÁFICA}

No Brasil a taxa de cesáreas é de $52 \%$ (OMS, 2015) refletindo o excesso de procedimentos feitos e caracterizando uma epidemia cesariana. A realização dessa prática cirúrgica sem indicações científicas tem maiores chances de ocasionar hemorragias, anemias, infecções pós-parto, infecções urinárias e complicações anestésicas (MASCARELLO K, et al., 2018). Desse modo, a tocofobia, a idade materna, as características socioeconômicas, a cultura e a escolaridade são os principais fatores que levam as gestantes a escolherem esse procedimento, já em relação aos médicos, estes julgam ser um procedimento mais rápido, seguro e lucrativo (FREITAS P, et al., 2015). Ademais, diante dos estudos constatados, a cesariana é um ótimo método para diminuir a morbidade e mortalidade materna e perinatal (PEREIRA R, et al., 2018) porém, quando realizadas com índices maiores de $15 \%$ a eficácia na redução da mesma não é evidente (OMS, 2015).

\section{CONSIDERAÇÕES FINAIS}

A prevalência de cesariana no país superior a $15 \%$ está relacionada às questões socioeconômicas, culturais, idade materna e grau de instrução escolar. Estes não são condizentes com a diminuição da mortalidade materno-infantil. Ademais, há maiores associações de complicações precoces e tardias. 


\section{REFERÊNCIAS}

1. FREITAS $P$, et al. $O$ parecer do Conselho Federal de Medicina, o incentivo à remuneração ao parto e as taxas de cesariana no Brasil. Cadernos de Saúde Pública, 2015; 31(9): 1839-1855.

2. MASCARELLO K, et al. Complicações puerperais precoces e tardias associadas à via de parto em uma coorte no Brasil. Revista Brasileira de Epidemiologia, 2018; 21: e180010.

3. PEREIRA R, et al. Novas práticas de atenção ao parto e os desafios para a humanização da assistência nas regiões sul e sudeste do Brasil. Revista Ciência \& Saúde Coletiva, 2018; 23(11): 3517-3524.

4. ZANARDO G, et al. Violência obstétrica no Brasil: uma revisão narrativa. Revista Psicologia \& Sociedade, 2017; 29: e155043.

5. OMS. Declaração da Organização Mundial da Saúde sobre Taxas de Cesáreas. Disponível em: http://apps.who.int/iris/bitstream/10665/161442/3/WHO_RHR_15.02_por.pdf. Acessado em: 22 de outubro de 2020. 
RESUMO SIMPLES: Revisão Bibliográfica

Título: Fatores de risco para a Gravidez Ectópica: uma revisão sistemática da literatura

Autor/coautores: Daniella Guelman Mesquita; Isabela Marcely de Jesus Gomes; Isabella Cristina Silva; Giovanna Mirela Guimarães; Daniela Camargos Costa de Souza.

Instituição: Faculdade de Minas - BH (FAMINAS-BH), Belo Horizonte - MG.

Palavras-chave: Gravidez ectópica, Fatores de risco, Mortalidade materna.

\section{INTRODUÇÃO}

A Gravidez Ectópica (GE) consiste na implantação e desenvolvimento do blastocisto fora do endométrio da cavidade uterina e, embora seja um evento raro, representa elevado risco de morte materna na rotina de emergência ginecológica (GASKIN AJ, et al., 2018). A tríade clássica para GE é representada por dor abdominal, sangramento vaginal e amenorreia. No entanto, muitas gestantes não apresentam sinais clássicos, sendo particularmente importante a apropriada caracterização dos fatores de risco para um diagnóstico rápido, minimizando as intervenções cirúrgicas e a evolução para o óbito materno (HOENDERBOOM BM, et al., 2019).

\section{OBJETIVO}

Determinar os fatores de risco para a gestação ectópica por meio de uma revisão da literatura a fim de nortear estratégias mais assertivas para a detecção precoce da GE e manejo oportuno da paciente.

\section{MÉTODO}

Foram utilizados os descritores "ectopic pregnancy" e "risk factors" na plataforma PubMed, onde foi possível obter 1582 artigos. Os critérios para a revisão foram: artigos experimentais, publicados em inglês, nos últimos dois anos, disponíveis gratuitamente, sendo possível obter 62 artigos. Foram excluídos artigos publicados antes de 2018, em outros idiomas, além do inglês e não disponibilizados de forma gratuita na plataforma. A partir da leitura dos títulos e resumos foram selecionados 12 artigos.

\section{REVISÃO BIBLIOGRÁFICA}

A GE é uma das emergências ginecológicas mais comuns, sendo as tubas uterinas o principal sítio de implantação, correspondendo a cerca de $90 \%$ de todas as gestações ectópicas descritas. Embora os avanços das pesquisas acerca do manejo da gestante e principalmente do diagnóstico precoce sejam responsáveis por uma significativa redução na mortalidade vinculada ao comprometimento supracitado, a rotura relacionada a GE continua a apresentar elevada mortalidade materna, sobretudo no primeiro trimestre (WANG X, et al., 2020). Para o presente estudo, foram obtidos 12 artigos, sendo cinco trabalhos de caso-controle, 5 de coorte e 2 relatos de caso. Foi possível observar que os fatores de risco mais frequentes nos estudos publicados nos dois últimos anos foram: uso de métodos contraceptivos ( 6 trabalhos), mulheres submetidas a tratamento para infertilidade (4), doença inflamatória pélvica (3) e tabagismo (2). A caracterização dos fatores de risco para GE é de grande relevância para determinar o diagnóstico e o tratamento oportunos, reduzindo o impacto deste comprometimento para a saúde da mulher (RANJI GG, et al., 2018).

\section{CONSIDERAÇÕES FINAIS}

A GE apresenta causa multifatorial, sendo de suma importância a caracterização de estudos epidemiológicos para determinar os fatores de risco relacionados a prenhez ectópica. Tais estudos se fazem 
necessários para nortear as políticas públicas de forma a minimizar sobretudo a elevada morbimortalidade materna.

\section{REFERÊNCIAS}

1. HOENDERBOOM BM, et al. Relation between Chlamydia trachomatis infection and pelvic inflammatory disease, ectopic pregnancy and tubal factor infertility in a Dutch cohort of women previously tested for chlamydia in a chlamydia screening trial. Sexually Transmitted Infections, 2019; 95: 300-306.

2. GASKIN AJ, et al. Demographic, lifestyle, and reproductive risk factors for ectopic pregnancy. Fertility and Sterilit, 2018; 110: 7.

3. RANJI GG, et al. Ectopic Pregnancy: Risk Factors, Clinical Presentation and Management. The Journal of Obstetrics and Gynecology of India, 2018; 68(6): 487-492.

4. WANG X, et al. Risk factors and clinical characteristics of recurrent ectopic pregnancy: A case-control study. The Journal of Obstetrics and Gynaecology Research, 2020; 46(7): 1098-1103. 
RESUMO SIMPLES: Revisão Bibliográfica

Título: Fatores que influenciam o impacto psicológico de parto de feto natimorto e morte neonatal nas gestantes

Autor/coautores: Ana Paula Diniz Gonçalves Drumond; Juliana Vieira Queiroz Almeida; Gabriela Sampaio Lima Araújo, Hugo Drumond Ribeiro.

Instituição: Faculdade de Minas - Belo Horizonte (FAMINAS-BH), Belo Horizonte - MG.

Palavras-chave: Natimorto, Gestante, Luto.

\section{INTRODUÇÃO}

O parto e o período gravídico são permeados de dúvidas e suas transformações impactam significativamente a vida da mulher (SAUVEGRAIN P e ZEITLIN J, 2020). Mediante isso, pode-se predizer que desfechos negativos, como parto de feto natimorto e morte neonatal podem ocasionar transtornos psíquicos as pacientes (SMITH LK, et al., 2020). Sendo assim, a atuação de profissionais de saúde mental é de extrema importância na condução da fase de luto tornando o menos extenso e doloroso. Ademais, os momentos pós-partos entre o binômio mãe-filho são preditores dos desfechos psicológicos da parturiente.

\section{OBJETIVO}

Pesquisar os fatores psicológicos de parturientes que vivenciaram parto de natimorto ou que vivenciaram a perda neonatal. Ademais, avaliar as mudanças nas relações intrafamiliares conjugais e expectativas de uma nova concepção seja para toda a família nuclear

\section{MÉTODO}

Revisão integrativa com busca na plataforma Pubmed, de artigos publicados a partir de 2019, em inglês. Descritores utilizados: "postpartum depression" e "neonatal death". Foram encontrados 12 artigos, sendo selecionados 6 . Foram incluídas publicações que abordavam aspectos psíquicos maternos após perda gestacional ou morte neonatal e excluídos os que não abordaram quais os impactos causados por estes eventos na saúde da mulher.

\section{REVISÃO BIBLIOGRÁFICA}

A necessidade de compreender os aspectos psicológicos que permeiam o período gravídico e puerperal tem se tornado cada vez mais reconhecida no âmbito do atendimento à saúde reprodutiva da mulher (RAVI $\mathrm{K}$, et al., 2020). Partos de natimortos, abortos espontâneos e morte perinatal acarretam transformações abruptas nos pais e familiares da paciente nas esferas biopsicossocial. Felizmente, a grande maioria dos pais concebem uma nova gestação, porém o concepto é permeado de inseguranças durante toda sua gestação impactando até a própria vida conjugal (CENA L e STEFANA A, 2020). Ademais, os cuidados no pós-parto, como o contato dos pais com o filho, ainda que sejam em um velório apresentam consequências psíquicas. Quando isso não ocorre, a falta da presença do filho é preenchida por sintomas físicos ou psíquicos (CHOUMMANIVONG M, et al., 2020). Consequente aos eventos foi notado: rompimento do relacionamento, separação ou divórcio dos pais após feto natimorto e gravidez subsequente conturbada (CENA L e STEFANA A, 2020).

\section{CONSIDERAÇÕES FINAIS}


A pequena amostra populacional é insuficiente e a inclusão dos familiares pode prejudicar a avaliação das ações de redução do impacto psicológico após o evento. É necessária abordagem empática, buscando entender as experiências e necessidade do casal, e estudos com amostra populacional mais significativa.

\section{REFERÊNCIAS}

1. CAMACHO-ÁVILA M, et al. Experience of parents who have suffered a perinatal death in two Spanish hospitals: a qualitative study. BioMed Central Pregnancy and Childbirth, 2019; 19(1): 512-512.

2. CENA L, STEFANA A. Psychoanalytic Perspectives on the Psychological Effects of Stillbirth on Parents: A Protocol for Systematic Review and Qualitative Synthesis. Frontiers in Psychology, 2020; 11: 12161256.

3. CHOUMMANIVONG M, et al. Stillbirth in Lao PDR: a healthcare provider perspective. Global Health Action, 2020; 13(sup2): 1786975.

4. RAVI K, et al. Why stillbirth deserves a place on the medical school curriculum: Stillbirth-related teaching in UK medical schools. BJOG: An international Journal of Obstetrics \& Gynaecology, 2020; 127(3): 414414.

5. SAUVEGRAIN P, ZEITLIN J. Investigating the benefits and challenges of including bereaved women in research: a multifaceted perinatal audit in a socially disadvantaged French district. British Medical Journal Open, 2020; 10: e034715.

6. SMITH LK, et al. Parents' experiences of care following the loss of a baby at the margins between miscarriage, stillbirth and neonatal death: a UK qualitative study. BJOG: An international Journal of Obstetrics \& Gynaecology, 2020; 127(7): 868-874. 
RESUMO SIMPLES: Revisão Bibliográfica

Título: Importância da biópsia do linfonodo sentinela no prognóstico do paciente com câncer de mama: uma revisão bibliográfica

Autor/coautores: Daniel Cruz Ferreira dos Reis ${ }^{2}$, Lilian Cavalcante Simal ${ }^{1}$, Polyana Fernandes Ruggio ${ }^{1}$, Raissa Lopes de Oliveira ${ }^{1}$.

Instituição: ${ }^{1}$ Faculdade de Minas - BH (FAMINAS - BH), Belo Horizonte - MG; ${ }^{2}$ Médico Cirurgião Geral no Hospital Santa Casa de Belo Horizonte - MG.

Palavras-chave: Axila, Câncer de mama, Linfonodo sentinela.

\section{INTRODUÇÃO}

O tumor mais frequente em mulheres brasileiras é o câncer de mama (CAVALCANTE FP, et al., 2020). Apesar de atualmente se evidenciar técnicas mais aprimoradas desde o diagnóstico até 0 tratamento, algumas técnicas ainda utilizadas não apresentam como as melhores opções, uma vez que possuem muitas contraindicações (CAVALCANTE FP, et al., 2020). Nessa perspectiva, a biópsia do linfonodo sentinela (BLS) se apresenta como um método eficaz em predizer o estado da axila e evitar o esvaziamento axilar nos pacientes sem comprometimento metastático (COSTA NETO OF, et al., 2017). Assim, substitui a necessidade de se realizar o esvaziamento axilar, diminuindo a incidência de complicações e a morbidade dos indivíduos quando submetidos ao tratamento de câncer de mama (COSTA NETO OF, et al., 2017).

\section{OBJETIVO}

Revisar a literatura científica constatando a importante relação do câncer de mama e a realização da biópsia de linfonodo sentinela. Este presente artigo foi baseado em pesquisas na plataforma Scielo e BVS, em português e inglês, onde selecionamos quatro artigos.

\section{REVISÃO BIBLIOGRÁFICA}

O câncer de mama é o mais comum entre as mulheres e o segundo mais frequente no mundo (CAVALCANTE FP, et al., 2020). A dissecção axilar ainda é controversa, pois, a maioria das pacientes são submetidas à cirurgia desnecessariamente, não apresentando metastização (COSTA NETO OF, et al., 2017). A linfadenectomia axilar completa possui uma elevada morbidade, como dormência (COSTA NETO OF, et al., 2017). O linfonodo sentinela (LS) drena um câncer de mama específica, com isso, se ocorrer disseminação linfática ele será o primeiro sitio a receber metástases (PAULINELLI RR, et al., 2017). O LS possui o intuito de estadiar a axila com menor morbidade, por meio da BLS, tem-se um método de amostragem axilar seletiva, minimamente invasivo e altamente sensível a identificar metástase, portanto, se o exame identificar que está livre de comprometimento tumoral, então o restante dos linfonodos da mesma axila tem baixa probabilidade de conter células tumorais (CAVALCANTE FP, et al., 2020). Segundo estudos a sobrevida global seria de $80 \%$ em 5 anos para mulheres tratadas de forma otimizada nos linfonodos positivos (GIULIANO AE, et al., 2017). O grupo BLS sozinho clinicamente seria considerado não inferior ao grupo de esvaziamento axilar se a taxa de sobrevida em 5 anos fosse de $75 \%$ ou mais (GIULIANO AE, et al., 2017).

\section{CONSIDERAÇÕES FINAIS}

A utilização da BLS no paciente diagnosticado com câncer de mama mostra-se eficiente no tratamento e no prognóstico da doença, pois assim evita os danos causados pela realização da linfadenectomia axilar, uma 
vez que o LS é um método minimamente invasivo e extremamente sensível na detecção de metástase, cessando possíveis comprometimentos tumorais.

\section{REFERÊNCIAS}

1. CAVALCANTE FP, et al. Progress in Local Treatment of Breast Cancer: A Narrative Review. Revista Brasileira de Ginecologia e Obstetrícia, 2020; 42(6): 356-364.

2. COSTA NETO OF, et al. Fatores preditivos de metástases axilares em pacientes com câncer de mama e biópsia de linfonodo sentinela positivo. Revista do Colégio Brasileiro de Cirurgiões, 2017; 44(4): 391-396.

3. GIULIANO AE, et al. Effect of Axillary Dissection vs No Axillary Dissection on 10-Year Overall Survival Among Women With Invasive Breast Cancer and Sentinel Node Metastasis The ACOSOG Z0011 (Alliance) Randomized Clinical Trial. Journal of the American Medical Association. 2017; 318(10): 918926.

4. PAULINELLI RR, et al. A prospective randomized trial comparing patent blue and methylene blue for the detection of the sentinel lymph node in breast cancer patients. Revista da Associação Médica Brasileira, 2017; 63(2): 118-123. 
RESUMO SIMPLES: Revisão Bibliográfica

Título: Importância do diagnóstico precoce da doença hipertensiva específica da gestação para o binômio mãe-feto

Autor/coautores: Pabline Vilela de Carvalho, Jennifer Kellen Souza, Bruna Silva Terra Diniz.

Instituição: Universidade José do Rosário Vellano (UNIFENAS), Belo Horizonte - MG.

Palavras-chave: Pré-eclâmpsia, Gravidez, Complicações cardiovasculares na gravidez.

\section{INTRODUÇÃO}

Dentre as síndromes hipertensivas gestacionais, a pré-eclâmpsia, ou doença hipertensiva específica da gravidez (DHEG), é o agravo mais importante durante a evolução do ciclo gravídico. Define-se pré-eclâmpsia como o desenvolvimento de hipertensão após a 20ª semana de gestação caracterizada pela pressão sistólica maior que $140 \mathrm{mmHg}$ e a diastólica maior que $90 \mathrm{mmHg}$ (CAMPOS A, et al., 2015). A DHEG ocorre, principalmente, em mulheres primíparas com idade nos extremos da fase reprodutiva e, dentre as complicações mais frequentes, estão a eclâmpsia e a síndrome HELLP, as quais podem ser evitadas com o diagnóstico precoce (SOARES MJ, et al., 2015).

\section{OBJETIVO}

Realizar uma revisão bibliográfica sobre a importância do diagnóstico precoce para a minimização de possíveis complicações da doença hipertensiva específica da gravidez e reduzir a mortalidade e morbidade materna e fetal.

\section{REVISÃO BIBLIOGRÁFICA}

Os principais achados que auxiliam no diagnóstico precoce de DHEG são: dor em região epigástrica, cefaleia, alterações visuais, taquipneia, hipertensão e proteinúria. Essa condição compromete o fluxo sanguíneo para o bebê e, assim, prejudica o seu desenvolvimento. No entanto, a doença pode evoluir de forma silenciosa, portanto, ao se suspeitar dessa condição, deve-se investigar minuciosamente (FERREIRA MBG, et al., 2016) (CAMPOS A, et al., 2015). Uma das complicações, relacionada ao diagnóstico tardio, é a síndrome HELLP (H: hemólise; EL: enzimas hepáticas elevadas; LP: contagem baixa de plaquetas), condição que aumenta os riscos de coagulação intravascular disseminada e descolamento prematuro da placenta (CAVALLI RC e CHÁVEZ JAD, 2016). Outra possível é a eclâmpsia, caracterizada pela presença de convulsão tônico-clônica generalizada e interrupção iminente da gestação (RUIZ MT, et al., 2015) (FERREIRA MBG, et al., 2016). O diagnóstico de pré-eclâmpsia em tempo hábil garante a abordagem focada em reduzir a morbimortalidade materna e fetal de acordo com o método PDCA (Planejar, Desenvolver, Implementar e Avaliar) ao convocar uma equipe multidisciplinar e estabelecer a terapia medicamentosa necessária (FERREIRA MBG, et al., 2016).

\section{CONSIDERAÇÕES FINAIS}

A maioria das complicações das mulheres com pré-eclâmpsia são evitáveis através do diagnóstico precoce e da prestação de cuidados eficientes. Assim, diante da seriedade dos distúrbios causados pela DHEG, destaca-se a importância da adoção da propedêutica investigante na prática clínica para a identificação dos sintomas com o intuito de impedir o agravamento da doença e, assim, reduzir a morbiletalidade materna $e$ fetal. 


\section{REFERÊNCIAS}

1. CAMPOS A, et al. Predição de pré-eclâmpsia no primeiro trimestre em gravidezes de baixo risco: determinação do cut-off numa amostra da população portuguesa. Acta Obstétrica e Ginecológica Portuguesa, 2015; 9(5): 366-373.

2. CAVALLI RC, CHÁVEZ JA. Preeclampsia: Vascular Pathophysiological Mechanism and the Basis for Early Diagnosis and Treatment. Thieme Open Access, 2016; 38(8): 369-372.

3. FERREIRA MBG, et al. Assistência de enfermagem a mulheres com pré-eclâmpsia e/ou eclâmpsia: revisão integrativa. Revista da Escola de Enfermagem da USP, 2016; 50(2): 320-330.

4. MELERE C, KERBER GF. Prevalência de síndromes hipertensivas gestacionais em usuárias de um hospital no sul do Brasil. Revista Cuidarte. 2017; 8(3): 1899-1906.

5. RUIZ MT, et al. Associação entre síndromes hipertensivas e hemorragia pós-parto. Revista Gaúcha de Enfermagem, 2015; 36(n.spe): 55-61.

6. SOARES M, et al. Prevalência das síndromes hipertensivas específicas da gestação (SHEG). Revista de Pesquisa: Cuidado é Fundamental Online, 2015; 7(3): 2717-2725. 
RESUMO SIMPLES: Revisão Bibliográfica

Título: Marcadores da reserva ovariana no contexto da reprodução assistida

Autor/coautores: Natália Corrêa da Silva, Ana Carolina Santos Ribeiro Mendes, Ana Luiza Lima Barcelos, Polyana Fernandes Ruggio, José Helvécio Kalil de Souza.

Instituição: Faculdade de Minas (FAMINAS - BH), Belo Horizonte - MG.

Palavras-chave: Reserva Ovariana, Técnicas de Reprodução Assistida, Hormônio Antimulleriano.

\section{INTRODUÇÃO}

A reserva ovariana prediz o potencial funcional do ovário, além do número e qualidade dos ócitos (SCHEFFER JAB, et al., 2018). Mulheres com baixa reserva ovariana podem ser consideradas inférteis e a avaliação da reserva é necessária nas pacientes que recorrem às técnicas de reprodução assistida, visto que possibilita verificar se responderão à estimulação ovariana (SCHEFFER JAB, et al., 2018). O envelhecimento é um conhecido marcador de baixa reserva ovariana, entretanto é preciso valer-se de outros testes. $O$ hormônio antimulleriano tem seu papel na reprodução e diferenciação sexual e é muito utilizado assim como a própria contagem de folículos antrais por meio do ultrassom transvaginal (TAKAE S, et al., 2017).

\section{OBJETIVO}

Revisar a literatura científica a respeito dos marcadores de reserva ovariana mais utilizados além de avaliar o quão fidedigno podem ser os testes e sua importância no contexto da reprodução assistida.

\section{REVISÃO BIBLIOGRÁFICA}

Os testes de reserva ovariana permitem avaliar a probabilidade da mulher engravidar de forma espontânea ou por técnicas de reprodução assistida (KANO M, et al., 2019). Nesse contexto, o hormônio antimulleriano (AMH) atua no desenvolvimento das gônadas e na diferenciação da crista urogenital. Além disso, atua na foliculogênese, ou seja, no recrutamento folicular primordial (KANO M, et al., 2019). É marcador preditivo da resposta ovariana à estimulação em pacientes com endometriose, aumentando as chances de fertilidade através da melhor abordagem de tratamento (SAFDARIAN L, et al., 2018). A contagem de folículo antral (AFC) e os níveis séricos de AMH parecem ser os preditores mais confiáveis do envelhecimento ovariano. Atualmente, a AFC é também um método muito utilizado na predição da fecundabilidade natural e com tendência semelhante ao AMH (KHAN HL, et al., 2019). As medidas de folículos antrais têm declínio com o aumento da idade, em avaliação tanto de mulheres férteis quanto inférteis com menos de 40 anos (KHAN HL, et al., 2019). No entanto, pode existir discordância entre valores de AMH e AFC. Assim, é possível observar que o AMH e AFC apresentam limitações na avaliação da reserva ovariana, principalmente de pacientes com reserva moderada e diminuída (ZHANG Y, et al., 2019).

\section{CONSIDERAÇÕES FINAIS}

Dentre os indicadores de reserva ovariana existentes, o AMH e AFC apresentam resultados semelhantes e são os métodos que mais se aproximam da reserva ovariana real. Contudo, podem ser identificadas discrepâncias entre as conclusões dos testes, principalmente por apresentarem caráter avaliador dependente. Desse modo, as mulheres que recorrem a reprodução assistida devem optar pelo método mais seguro em relação aos resultados obtidos, fomentando as chances de êxito do procedimento. 


\section{REFERÊNCIAS}

1. TAKAE S, et al. Accuracy and safety verification of ovarian reserve assessment technique for ovarian tissue transplantation using optical coherence tomography in mice ovary. Scientific Reports, 2017; 7: 43550.

2. KANO M, et al. AMH/MIS as a contraceptive that protects the ovarian reserve during chemotherapy. Proceedings of the National Academy of Sciences, 2017; 114(9): 1688-1697.

3. KHAN HL, et al. Antral follicle count (AFC) and serum anti-Müllerian hormone (AMH) are the predictors of natural fecundability have similar trends irrespective of fertility status and menstrual characteristics among fertile and infertile women below the age of 40 years. Reproductive Biology and Endocrinology, 2019; 17(1): 20-32.

4. SCHEFFER JAB, et al. Are age and anti-Müllerian hormone good predictors of ovarian reserve and response in women undergoing IVF? JBRA Assisted Reproduction, 2018; 22(3): 215-220.

5. ZHANG Y, et al. Discordance between antral follicle counts and anti-Müllerian hormone levels in women undergoing in vitro fertilization. Reproductive Biology and Endocrinology, 2019; 17(1): 51-56.

6. SAFDARIAN L, et al. Investigation anti-Mullerian hormone (AMH) and ovarian response in infertile women with endometriosis in IVF cycles. International Journal Reproductive Biomedicine, 2018; 16(11): 719-722. 
RESUMO SIMPLES: Revisão Bibliográfica

Título: Mecanismos de orte materna ocasionados pela pré-eclâmpsia

Autor/coautores: Amanda Godinho Machado¹, Anna Clara Silva Fonseca1', Kecyanne Malheiros Machado², Yanná Malheiros Machado ${ }^{1}$, Rayana Rolla Campos' ${ }^{1}$.

Instituição: Faculdade de Minas - FAMINAS - $\mathrm{BH}^{1}$, Belo Horizonte - MG; Universidade José do Rosário Vellano - UNIFENAS², Belo Horizonte - MG.

Palavras-chave: Pré-eclâmpsia, Morte materna, Complicações da pré-eclâmpsia.

\section{INTRODUÇÃO}

A pré-eclâmpsia (PE) é classificada como uma síndrome multissistêmica gestacional, normalmente manifestada após a $20^{\underline{a}}$ semana, sendo caracterizada por hipertensão associada à proteinúria e a outros sinais sistêmicos, acometendo geralmente de 3 a $7 \%$ das gestantes. A sua fisiopatologia ainda é desconhecida, mas as suas complicações incluem acidente vascular encefálico; insuficiências cardíacas, hepática, renal; edema pulmonar e coagulopatias. A PE está relacionada ao aumento do risco de morte fetal/neonatal, à restrição de crescimento intrauterino e ao parto prematuro devido à insuficiência placentária (PERAÇOLI JC, et al., 2019) (SANDRIM VC, et al., 2020).

\section{OBJETIVO}

Revisar sobre os principais mecanismos de morte materna ocasionados pela pré-eclâmpsia, sua fisiopatologia e os principais fatores de risco, além de enfatizar a importância do diagnóstico e tratamento precoces, suas complicações e consequências na saúde da mulher e do bebê.

\section{MÉTODO}

Realizado no formato de revisão integrativa, abrangeu artigos científicos das bases de dados Scielo e sites governamentais. Foram utilizados os descritores "pré-eclâmpsia", "morte materna" e "complicações da préeclâmpsia". Os critérios de inclusão foram artigos publicados entre 2015 e 2020. Foram pré-selecionados 10 artigos e, destes, 6 foram selecionados, sendo 4 da Scielo e 2 de sites governamentais.

\section{REVISÃO BIBLIOGRÁFICA}

\section{EPIDEMIOLOGIA}

A pré-eclâmpsia é responsável pelo óbito de aproximadamente 76.000 mães/ano, sendo causa de $25 \%$ das mortes maternas na América Latina e afetando de 5 a 7\% das gestantes brasileiras (BRASIL,2019).

\section{FATORES DE RISCO}

Nuliparidade, hipertensão crônica, obesidade, gestação múltipla, trombofilias, colagenoses, etnia negra, doença renal, diabetes gestacional, lúpus sistêmicos, histórico familiar, eclâmpsia, doenças cardiovasculares, concepção in vitro e índice de massa corporal elevado (RAMOS JGL, et al., 2017) (KAHHALE S, et al., 2018)

\section{FISIOPATOLOGIA}

A exata fisiopatologia ainda é desconhecida e estudada, mas a má adaptação imunológica ao trofoblasto causaria hipóxia, a reoxigenação local levaria ao estresse oxidativo e à inflamação crônica que, com vasoespasmos das arteríolas placentárias, diminuiria o fluxo sanguíneo para o bebê (BRASIL, 2020).

\section{COMPLICAÇÕES}


Podem ocorrer nos sistemas cardiovascular, hematológico, neurológico, renal, hepático, placentário, oftalmológico e hidroeletrolítico. Há acréscimo de $20 \%$ de risco de morte por doença cardiovascular. O risco aumenta quando o diagnóstico é realizado em idades gestacionais precoces (RAMOS JGL, et al., 2017).

\section{CONSIDERAÇÕES FINAIS}

A pré-eclâmpsia ocasiona diversas complicações e mecanismos de morte materna. Dispondo o prognóstico tardio agravado, pode gerar a pré-eclâmpsia recorrente futura doença cardiovascular. Sendo notória a importância do diagnóstico e tratamento precoces, acompanhamento e orientações essenciais à gestação e ao puerpério.

\section{REFERÊNCIAS}

1. BRASIL. Governo de Santa Catarina. Secretaria de Estado da Saúde. A Pré-eclâmpsia afeta até $7 \%$ das brasileiras. Disponível em https://www.saude.sc.gov.br/index.php/noticias-geral/todas-as-noticias/1641noticias-2019/10661-a-pre-eclampsia-afeta-ate-7-das-brasileiras. Acessado em 23 de maio de 2019.

2. KAHHALE S, et al. Pré-eclâmpsia. Revista Médica. São Paulo. 2018; 97(2): 226-34.

3. BRASIL. Manual - Versão para Profissionais da Saúde. Pré-Eclâmpsia e Eclâmpsia, 2020. Disponível em: <https://www.msdmanuals.com/pt-pt/profissional/ginecologia-e-obstetr\%C3\%ADcia/anormalidadesna-gestação/pré-eclâmpsia-e-eclampsia>. Acessado em 28 de outubro de 2020.

4. PERAÇOLI JC, et al. Pre-eclampsia/eclampsia. Revista Brasileira de Ginecologia e Obstetrícia, 2019; 41(5): 318-332.

5. RAMOS JGL, et al. Pré-eclâmpsia nos seus diversos aspectos. Série, orientações e recomendações Federação Brasileira das Associações de Ginecologia e Obstetrícia (FEBRASGO). São Paulo. n. 8, 2017.

6. SANDRIM VC, et al. Interação entre NOS3 e HMOX1 na responsividade a medicamentos antihipertensivos na pré-eclâmpsia. Revista Brasileira de Ginecologia e Obstetrícia, Rio de Janeiro. 2020; 42(8). Epub 25 de setembro de 2020. 
RESUMO SIMPLES: Revisão Bibliográfica

Título: Mulheres grávidas infectadas com covid-19: riscos aumentados?

Autor/coautores: Guilherme Eugênio Gil; Letícia Gomes Fabri Dourado; Márcia Rocha Gabaldi Silva.

Instituição: Universidade de Marília (UNIMAR), Marília - SP.

Palavras-chave: "Pregnancy", "Covid-19", "Sars-cov-2".

\section{INTRODUÇÃO}

Os primeiros casos do novo coronavírus, surgiram no final do ano de 2019 em Wuhan (China) (RYAN GA, et al., 2020). Com o avanço da doença por diversos países, foram necessárias mudanças, como o uso de máscaras e o isolamento social. Houve então a preocupação em relação a mulheres grávidas infectadas sobre as consequências da ação do vírus (MASMEJAN S, et al., 2020). Nas grávidas infectadas analisadas ocorreu um maior risco de vulnerabilidade (MASMEJAN S, et al., 2020) com desenvolvimento de pneumonia, febre, tosse e linfopenia, e casos em que foi necessário o uso da Unidade de Terapia Intensiva (UTI) e ventilação mecânica (CASTRO P, et al., 2020).

\section{OBJETIVOS}

Revisar a literatura científica de artigos que mostram estudos sobre a situação das mulheres grávidas infectadas com covid-19 e o quadro apresentado por elas durante a pandemia do novo coronavírus. E assim realizar uma revisão narrativa dos artigos selecionados.

\section{REVISÃO BIBLIOGRÁFICA}

Nos estudos analisados foi possível constatar que as mulheres grávidas apresentam certa vulnerabilidade a infecção da covid-19 (MASMEJAN S, et al., 2020). Dados de outras pandemias foram analisados para comparar sobre o desenvolvimento de doenças respiratórias em mulheres grávidas, devido à preocupação com esse grupo e a falta de informações do novo vírus (MASMEJAN S, et al., 2020). O desenvolvimento de pneumonia em mulheres grávidas infectadas pelo coronavírus e uso da UTI e de ventiladores mecânicos foi observado em alguns casos (RASMUSSEN AS, et al., 2020). Mulheres grávidas com pneumonia possuem maiores chances de terem partos prematuros (WENLING Y, et al., 2020). Ainda não há evidências dos riscos da transmissão vertical entre mãe com covid-19 e o bebê nascido (ALBERCA RW, et al., 2020). O vírus desencadeia alterações no corpo, incluindo uma série de respostas imunológicas, ocorrendo até mesmo alterações histológicas na placenta de gestantes infectadas (WENLING Y, et al., 2020).

\section{CONSIDERAÇÕES FINAIS}

Mulheres grávidas infectadas com covid-19 apresentam alterações em seu organismo, representados por sintomas típicos da doença e por formas mais graves devido alterações em seu corpo em resposta a infecção. Por ser um vírus novo não há muitas informações ainda, por esse motivo a análise de estudos anteriores de outros vírus de doenças respiratórias torna-se importante, assim como mais estudos devem ser realizados.

\section{REFERÊNCIAS}

1. ALBERCA RW, et al. Pregnancy, Viral Infection, and COVID-19. Front Immunol. 2020; 11:1672. 
2. CASTRO P, et al. Covid-19 and Pregnancy: An Overview. Covid-19 e gravidez: Uma visão geral. Rev Bras Ginecol Obstet. 2020; 42(7): 420-426.

3. MASMEJAN S, et al. COVID-19 et grossesse [COVID-19 and pregnancy]. Rev Med Suisse. 2020; 16(692): 944-946.

4. RASMUSSEN AS, et al. Coronavirus Disease 2019 (COVID-19) and pregnancy: what obstetricians need to know. Am J Obstet Gynecol. 2020; 222(5): 415-426.

5. RYAN GA, et al. Clinical update on COVID-19 in pregnancy: A review article. J Obstet Gynaecol Res. 2020; 46(8): 1235-1245.

6. WENLING Y, et al. Pregnancy and COVID-19: management and challenges. Rev Inst Med Trop Sao Paulo. 2020; 62: e62. 
RESUMO SIMPLES: Revisão Bibliográfica

Título: O Cannabidiol para manejo de dor em pacientes com endometriose

Autor/coautores: Alice França Clemente; Ana Clara Dias Resende Chaves; Fernanda Pimenta Fernandes.

Instituição: Faculdade Ciências Médicas de Minas gerais (FCMMG), Belo Horizonte - MG.

Palavras-chave: Endometriose, Dor Pélvica Crônica, Cannabidiol.

\section{INTRODUÇÃO}

A endometriose é uma condição crônica, benigna, inflamatória, estrógeno-dependente, caracterizada pela presença de tecido endometrial extrauterino. Embora sua etiopatogenia não seja completamente elucidada, estudos indicam que fatores genéticos, hormonais e imunológicos contribuem para a formação e o desenvolvimento dos focos ectópicos de endometriose (NOGUEIRA ACR, 2018). Sua clínica é muito variada, porém em $56,8 \%$ dos casos é relatado dor pélvica crônica. Nesse contexto, os tratamentos medicamentosos vêm se mostrando ineficientes por haver uma grande porcentagem de recorrência ou alívio parcial dos sintomas. Assim, o uso de cannabidiol se mostra relevante para aliviar a dor nesses casos (BOUAZIZ J, et al., 2017).

\section{OBJETIVO}

Revisar a literatura científica envolvendo o uso de cannabidiol para manejo da dor no tratamento de pacientes com endometriose, elucidando se essa opção terapêutica é realmente mais vantajosa e eficaz que os tratamentos medicamentos mais utilizados atualmente.

\section{MÉTODO}

Revisão sistemática realizada em setembro de 2020, nas bases de dados PubMed e Google Scholar, usando como descritores "cannabidiol", "endometriose", "dor pélvica crônica", selecionando artigos publicados entre 2015 e 2020, em inglês ou português. Entre as publicações encontradas, foram selecionados 3 artigos para a construção do presente estudo. Foram incluídos artigos que se enquadravam nas especificações descritas e foram excluídos relatos de casos, editoriais, trabalhos incompletos e sem relevância temática.

\section{REVISÃO BIBLIOGRÁFICA}

A endometriose envolve três principais mecanismos de dor: a ativação de nociceptores pela compressão mecânica de nervos causada pelas lesões no endométrio, o aumento de citocinas e outros fatores responsáveis por um estímulo inflamatório de hipersensibilidade e estresse oxidativo, além de dor neuropática por dano direto a neurônios. Além disso, muitas pacientes experienciam o surgimento de fatores psicológicos que culminam para a amplificação da sensação dolorosa (BOUAZIZ J, et al., 2017). Evidências mostraram que pacientes com endometriose apresentam uma redução significativa de receptor canabinóide tipo 1 no tecido endometrial, prejudicando a capacidade de controle de dor nessas pacientes. Nesse sentido, por meio da modulação da produção de citocinas e da regulação da função de receptores canabinóides, os agonistas dos receptores canabinóides apresentam função anti-inflamatória, que potencialmente possibilitam o controle do crescimento da lesão endométrica e da dor (TANAKA K, et al., 2020).

\section{CONSIDERAÇÕES FINAIS}


Essa finalidade para o cannabidiol ainda é um assunto recente e, portanto, apresenta limitações, sobretudo relacionadas ao efeito de cada dose de cannabidiol nas investigações. Contudo, o uso demonstra ser promissor para a terapêutica de pacientes com endometriose, principalmente no manejo da dor.

\section{REFERÊNCIAS}

1. BOUAZIZ J, et al. The clinical significance of endocannabinoids in endometriosis pain management. Cannabis and Cannabinoid Research, 2017; 2(1): 72-80.

2. NOGUEIRA ACR, et al. Tratamento da endometriose pélvica: uma revisão sistemática. Revisa Científica FAGOC-Saúde, 2018; 3(2): 38-43.

3. TANAKA K, et al. The role of the endocannabinoid system in aetiopathogenesis of endometriosis: A potential therapeutic target. European journal of obstetrics \& gynecology and reproductive biology, 2020; 244: 87-94. 
RESUMO SIMPLES: Revisão Bibliográfica

Título: Pandemia covid 19 e o aumento da violência contra mulher

Autor/coautores: Rafaella Carvalho Barbosa Vieira; Adenir Junio Silva Santos; Danilo Cunha Meirelles; Nayara Neves de Alcântara; Joana Carolina de Resende Paula.

Instituição: Faculdade da Saúde e Ecologia Humana (FASEH). Vespasiano - MG.

Palavras-chave: Violência doméstica; Violência contra a mulher; COVID-19.

\section{INTRODUÇÃO}

A violência contra a mulher consiste em qualquer ato com dano físico, sexual ou psicológico, sendo considerado um fenômeno multifatorial e um problema de saúde pública. Quando o tipo de violência diz respeito à doméstica, certos fatores podem aumentar o risco como, violência doméstica prévia, idade jovem, casais com disparidade de renda, escolaridade ou status profissional (SANTOS IB, et al., 2020). Diante desses fatores, surgiu a reflexão da relação da Pandemia do COVID-19 e medidas de isolamento domiciliar que afetam mulheres vítimas de violência doméstica (BRASIL, 2020). Com isso é importante para uma abordagem inicial a essas mulheres uma equipe de saúde qualificada a prestar assistência em âmbito biopsicossocial (GARCIA-MORENO C, et al., 2015).

\section{OBJETIVO}

Revisar na literatura artigos sobre a violência doméstica contra mulher para análise da epidemiologia, dos fatores de risco, da importância da abordagem precoce e refletir sobre o aumento da vulnerabilidade da mulher em tempo de pandemia da COVID-19.

\section{MÉTODO}

Revisão sistemática de literatura por meio de busca de artigos científicos com os descritores "women's Health", "Violence Against Women", "Domestic Violence", "Pandemics" nas plataformas PubMed e Scielo. Incluídos os artigos com textos completos em português e inglês publicados nos últimos cinco anos, e documentos ou textos de associações e sociedades científicas relacionados ao tema. Exclui-se artigos com textos incompletos e publicados há mais de cinco anos.

\section{REVISÃO BIBLIOGRÁFICA}

A violência doméstica contra a mulher é um problema de Saúde Pública. No Brasil, estudos mostram que $43 \%$ das brasileiras declararam ter sofrido pelo menos um ato de violência por parceiro íntimo na vida, sendo um terço violência física, $13 \%$ sexual e $27 \%$ psicológica (SANTOS IB, et al., 2020). Atualmente, com o isolamento social pela Pandemia da Covid-19, surgiram situações que agravam tais índices, como maior convívio com o cônjuge agressor e falta de apoio de outras mulheres e entidades (BRASIL, 2020). Certos grupos são mais vulneráveis, devido ao histórico de violência doméstica, idade jovem, disparidade de renda, escolaridade ou status profissional. Além disso, alguns perfis estão associados ao comportamento agressivo, como exposição do agressor à violência infantil, abuso de substância, perda recente de emprego ou instabilidade. É comum na investigação inicial, a paciente não ser colaborativa e negar qualquer tipo de violência por diversos motivos, inclusive culturais (SANTOS IB, et al., 2020). Por isso é importante que os profissionais de saúde tenham atenção nos sinais clínicos que levantam suspeita de violência e visando proteger a mulher vulnerável, os meios de denúncia e apoio às vítimas devem ser fortalecidos (GARCIAMORENO C, et al., 2015) (O'DOHERTY L, et al., 2015) (SUMNER SA, et al., 2015). 


\section{CONSIDERAÇÕES FINAIS}

Pelo exposto, a violência doméstica afeta número significativo de mulheres e é um problema de saúde pública. Por isso, uma equipe bem capacitada e instruída é capaz de identificar e ter a abordagem necessária para ajudar essas vítimas. A assistência necessária é fundamental para tirar as mulheres dessa situação de risco e minimizar os impactos causados pela violência.

\section{REFERÊNCIAS}

1. BRASIL. Fiocruz. Fundação Oswaldo Cruz, Minas - Mulheres, violência e pandemia de coronavírus. Disponível em: http://www.cpqrr.fiocruz.br/pg/artigo-mulheres-violencia-e-pandemia-de-coronavirus/. Acessado em: 28 de outubro de 2020.

2. GARCIA-MORENO C, et al. The health-systems response to violence against women. The Lancet, 2015; 385(9977): 1567-1579.

3. O'DOHERTY L, et al. Screening Women for Intimate Partner Violence in Healthcare Settings. Cochrane Database of Systematic Reviews, 2015; 7.

4. SANTOS IB, et al. Violência contra a mulher na vida: estudo entre usuárias da atenção primária. Ciência \& Saúde Coletiva, 2020; 25(5): 1935-1946.

5. SUMNER SA, et al. Violence in the United States. Jama, 2015; 314(5): 478-480. 
RESUMO SIMPLES: Revisão Bibliográfica

Título: Redução do impacto psicológico para a gestante: feto natimorto e morte neonatal

Autor/coautores: Gabriela Sampaio Lima Araújo; Juliana Vieira Queiroz Almeida; Ana Paula Diniz Gonçalves Drumond; Hugo Drumond Ribeiro.

Instituição: Faculdade de Minas - Belo Horizonte (FAMINAS-BH), Belo Horizonte - MG.

Palavras-chave: Natimorto, Gestante, Luto.

\section{INTRODUÇÃO}

Desfechos negativos gestacionais, como morte neonatal e parto de feto natimorto, prejudicam a saúde mental feminina (CENA L e STEFANA A, 2020). A taxa global de mortalidade neonatal (CENA L e STEFANA A, 2020) e de nascimento de feto natimorto é de 2,5 milhões/ano cada, ou seja, 18,4 por 1000 nascidos vivos/ano (CHOUMMANIVONG M, et al., 2020). O luto pode durar 2 anos, afetando a vida socioeconômica e psicológica do casal, sendo que profissionais da saúde devem apoiar psicologicamente e reduzir o impacto do evento para o casal enlutado (CENA L e STEFANA A, 2020).

\section{OBJETIVO}

Avaliar as estratégias e mudanças no atendimento que podem reduzir o impacto psicológico para o casal e para a gestante que realizou parto com feto natimorto ou vivenciou morte neonatal.

\section{MÉTODO}

Revisão integrativa com busca na plataforma Pubmed com descritores: "postpartum depression" e "neonatal death". Foram encontrados 12 artigos, publicados a partir de 2019, em inglês, sendo selecionados 6. Incluiu-se publicações que abordavam aspectos psíquicos maternos após perda gestacional ou morte neonatal e excluídas as que não abordaram métodos para redução do impacto psicológico.

\section{REVISÃO BIBLIOGRÁFICA}

O luto perinatal envolve aspectos biológicos, psicológicos, sociais e espirituais, sendo necessário apoio familiar e abordagem multidisciplinar para evitar distúrbios alimentares e do sono, doenças crônicas e pior qualidade de vida, relacionada a ansiedade, depressão e transtorno de estresse pós-traumático. É necessário reduzir agravantes da dor, como: linguagem não verbal negativa, tensão dos profissionais da saúde, falta de informações e empatia, dor do parto quando morte prévia ao nascimento, solidão, demora do resultado e resultado inconclusivo da autópsia e ausência de rituais de luto e identificação do bebê (CAMACHO-ÁVILA M, et al., 2019). A coleta de artefatos, o uso de palavras diferentes de "feto", o preparo para o parto, nascimento e provável aparência da criança favorecem a formação de memórias positivas. A ausência de preparo para sintomas pós-natais aumenta a percepção deles, podendo haver exaustão física, desolamento e pânico (SMITH LK, et al, 2020). Houve benefício na presença de grupo de apoio para as gestantes (SAUVEGRAIN P e ZEITLIN J, 2020) e cuidado adequado do casal em luto (RAVI K, et al., 2019).

\section{CONSIDERAÇÕES FINAIS}

A pequena amostra populacional e insuficiente inclusão dos familiares pode prejudicar a avaliação das ações de redução do impacto psicológico após o evento. É necessária abordagem empática, buscando entender as experiências e necessidade do casal, e estudos com amostra populacional mais significativa. 


\section{REFERÊNCIAS}

1. CAMACHO-ÁVILA M, et al. Experience of parents who have suffered a perinatal death in two Spanish hospitals: a qualitative study. BioMed Central Pregnancy and Childbirth, 2019; 19(1): 512-512.

2. CENA L, STEFANA A. Psychoanalytic Perspectives on the Psychological Effects of Stillbirth on Parents: A Protocol for Systematic Review and Qualitative Synthesis. Frontiers in Psychology, 2020; 11: 12161216.

3. CHOUMMANIVONG M, et al. Stillbirth in Lao PDR: a healthcare provider perspective. Global Health Action, 2020; 13(sup2): 1786975.

4. RAVI K, et al. Why stillbirth deserves a place on the medical school curriculum: Stillbirth-related teaching in UK medical schools. BJOG: An international Journal of Obstetrics \& Gynaecology, 2020; 127(3): 414414.

5. SAUVEGRAIN P, ZEITLIN J. Investigating the benefits and challenges of including bereaved women in research: a multifaceted perinatal audit in a socially disadvantaged French district. British Medical Journal Open, 2020; 10: e034715.

6. SMITH LK, et al. Parents' experiences of care following the loss of a baby at the margins between miscarriage, stillbirth and neonatal death: a UK qualitative study. BJOG: An international Journal of Obstetrics \& Gynaecology, 2020; 127(7): 868-874. 
RESUMO SIMPLES: Revisão Bibliográfica

Título: Repercussões vasculares na gestação de mulheres com anemia falciforme

Autor/coautores: Luisa de Sousa Mattos, Luisa de Aguiar Magalhães Murta ${ }^{1}$, Mariana de Sena Milagres Signorelli ${ }^{1}$, Maria Clara Brant Rocha ${ }^{1}$, Moacyr Eduardo Generoso Brandão Murta².

Instituição: ${ }^{1}$ Faculdade Ciências Médicas de Minas Gerais (FCMMG), Belo Horizonte - MG; ${ }^{2}$ Hospital Madre Teresa, Belo Horizonte - MG.

Palavras-chave: Anemia falciforme; Repercussões; Gestação.

\section{INTRODUÇÃO}

A anemia falciforme (AF) é uma hemoglobinopatia, de herança autossômica recessiva, caracterizada por uma mutação na posição seis da cadeia beta-globina, resultando na produção de uma hemoglobina defeituosa (HbS) (CATHI P e MARGARET B, 2017). Essa modificação altera a estrutura das hemácias, prejudicando o transporte de oxigênio, além de trazer repercussões como a anemia hemolítica crônica e oclusão vascular (XIOMARA PL e LALA LVR, 2016). Assim, a gravidez para mulheres com AF é de alto risco e associa-se à alta morbimortalidade materna e fetal (CATHI P e MARGARET B, 2017).

\section{OBJETIVO}

Revisar a literatura científica acerca das repercussões cardiovasculares na gestação de mulheres com AF, discutindo a fisiopatologia da doença de base e suas apresentações clínicas materno-fetais na gravidez.

\section{MÉTODO}

Revisão integrativa da literatura, realizada durante outubro de 2020, sendo os descritores: "sickle cell disease", "pregnancy", "maternal outcomes", "perinatal outcomes". A busca dos 5 artigos seguiu os seguintes critérios de inclusão: artigos originais, disponíveis nas bases de dado SciELO e PubMed, em inglês e espanhol, publicados entre 2016 e 2019, sendo excluídos artigos publicados antes de 2016.

\section{REVISÃO BIBLIOGRÁFICA}

O estado hipercoagulável da gravidez aumenta o risco de eventos tromboembólicos nas gestantes com AF e o aumento do débito cardíaco pode comprometer a estabilidade cardiovascular delas, especialmente as que possuem hipertensão pulmonar (CATHI P e MARGARET B, 2017). Essas repercussões aumentam o risco de desenvolver hipertensão e pré-eclâmpsia (NABILAH FL, et al., 2017). A principal complicação perinatal é o retardo do crescimento intrauterino (MANUELA FHC, et al., 2018). Isso ocorre, principalmente, pois a placenta é afetada pela anóxia tissular e o resultado é uma hipóxia fetal crônica. (XIOMARA PL e LALA LVR, 2016). Um estudo realizado de 2007 a 2017 avaliou o programa de rastreamento pré-natal de células falciformes e talassemia na Inglaterra, em que foram identificadas 154.196 mulheres portadoras da AF. Constatando-se que o rastreio precoce dessa anemia nas gestantes contribuiu para uma redução da mortalidade infantil e oferece tempo para a gestante considerar suas opções em relação a gravidez (WEIL LG, et al., 2020).

\section{CONSIDERAÇÕES FINAIS}

$O$ avanço da medicina proporcionou um aumento da sobrevida de pacientes com AF, assim, mais portadoras da doença chegam à idade reprodutiva. Contudo, essa gestação é marcada por adversidades, 
sendo a compreensão epidemiológica das repercussões fundamentais para aprimorar o cuidado nessa área. Entretanto, estudos voltados a AF na gravidez são escassos e devem ser encorajados.

\section{REFERÊNCIAS}

1. CATHI P, MARGARET B. Perinatal and Neonatal Implications of Sickle Cell Disease. Nursing for Women's Health, 2017; 21(6): 476-486.

2. MANUELA FHC, et al. Chemokines in pregnant women with sickle cell disease. Cytokine, 2018; 113: 15.

3. NABILAH FL, et al. The emerging challenge of optimal blood pressure management and hypertensive syndromes in pregnant women with sickle cell disease: a review. Expert Review of Hematology, 2017; 10(11): 1-28.

4. WEIL LG. et al. Sickle cell disease and thalassaemia antenatal screening programme in England over 10 years: a review from 2007/2008 to 2016/2017. Journal of clinical pathology, 2019; 73(4): 183-190.

5. XIOMARA PL, LALA LVR. Enfermedad de células falciformes en el embarazo. Revista Cubana de Obstetricia y Ginecología, 2016; 42(2): 239-253. 
RESUMO SIMPLES: Revisão Bibliográfica

Título: Síndrome semelhante a pré-eclâmpsia induzida por Covid-19 grave: uma revisão da literatura

Autor/coautores: Débora Rodrigues Tolentino, Bianca Rodrigues Tavares, Inês Clara Martins de Souza, Samuel Melo Ribeiro, Joana Carolina de Resende Paula.

Instituição: Faculdade da Saúde e Ecologia Humana, Belo Horizonte - MG.

Palavras-chave: Vírus Corona, Gravidez, Pré-Eclâmpsia.

\section{INTRODUÇÃO}

O Coronavírus-2019 (COVID-19), foi declarada pela Organização Mundial da Saúde (OMS) uma doença pandêmica, causada pelo vírus SARS-CoV-2, com alta transmissibilidade, principalmente por gotículas. Suas manifestações clínicas variam de leves a graves (ESAKANDARI $\mathrm{H}$, et al., 2020). Durante a gravidez alterações imunológicas podem aumentar o risco com a exposição à doença, com isso, o Ministério da Saúde (MS) passou a considerar as gestantes grupo de risco (ELLINGTON S, et al., 2020). Embora poucos estudos sobre complicações na gravidez associada a COVID-19, foram descritos achados clínicos laboratoriais de síndrome semelhante a pré-eclâmpsia (PE) e à síndrome HELLP em gestantes infectadas (MENDOZA M, et al., 2020). Por isso, faz-se necessário diagnóstico adequado considerando sua gravidade.

\section{OBJETIVO}

Revisar a literatura disponível a fim de elucidar a relação da COVID-19 com a PE e a síndrome HELLP, buscando alcançar melhor entendimento da fisiopatologia abrangida, considerando a problemática que envolve a gravidez como fator de risco para a COVID-19.

\section{MÉTODO}

Trata-se de uma revisão integrativa da literatura. Foram selecionados 5 artigos científicos publicados no ano atual, nas bases de dados Scielo, PubMed e Google Scholar, em inglês e português. Critérios de inclusão: artigos recentes e de maior relevância. Excluídos os artigos que não contemplavam o tema.

\section{REVISÃO BIBLIOGRÁFICA}

Em mulheres grávidas, algumas alterações laboratoriais relacionadas à COVID-19, como a hemólise, níveis elevados de enzimas hepáticas e baixos níveis plaquetários, são semelhantes às que ocorrem na préeclâmpsia com características graves e na síndrome HELLP (MENDOZA M, et al., 2020). Essas alterações incluem o tempo de protrombina prolongado; níveis elevados de dímero $D$, procalcitonina e proteína $C$ reativa (PCR); e baixos níveis de fibrinogênio também podem ser observados em COVID-19 (observe que os intervalos de referência para D-dímero, PCR e níveis de fibrinogênio são mais elevados em mulheres grávidas). Cefaléia, doença cerebrovascular aguda e convulsões podem ser manifestações neurológicas de COVID-19, bem como achados da pré-eclâmpsia com características graves: eclâmpsia (BERGHELLA V e HUGHES B, 2020). O principal desafio imposto aos cuidadores ocorre, então, devido à coincidência dos critérios diagnósticos, o que dificulta a diferenciação entre as patologias. Essa diferenciação é de extrema importância pois reflete diretamente no manejo e prognóstico materno-fetal (MENDOZA M, et al., 2020).

\section{CONSIDERAÇÕES FINAIS}

A COVID-19 é uma condição imunológica marcada por linfócitos reduzidos e citocinas pró-inflamatórias aumentadas. A resposta imune gestacional aumenta o risco para COVID-19, sendo que, mulheres grávidas 
com COVID-19 grave podem desenvolver síndrome semelhante à PE. Portanto, os profissionais de saúde devem estar cientes dessa condição para melhor condução dos casos.

\section{REFERÊNCIAS}

1. BERGHELLA V, HUGHES B. Coronavirus disease 2019 (COVID-19): Pregnancy issues and antenatal care. In: LOCKWOOD, C.J. ed. UpToDate. Waltham, Mass.: UpToDate, 2020; 1-33.

2. ESKANDARI H, et al. A comprehensive review of COVID-19 characteristics, 2020; 2: 1-10.

3. ELLINGTON S, et al. Characteristics of Women of Reproductive Age with Laboratory-Confirmed SARSCoV-2 Infection by Pregnancy Status - United States, January 22-June 7, 2020. MMWR. Morbidity and Mortality Weekly Report, 2020; 69: 769-775

4. MENDOZA M, et al. Pre-eclampsia-like syndrome induced by severe COVID-19: a prospective observational study. BJOG: An International Journal of Obstetrics and Gynaecology, 2020; 127: 13741380.

5. RICHTMANN R, et al. Fetal deaths in pregnancies with SARS-CoV-2 infection in Brazil: A case series. Case Reports in Women's Health, 2020; 27: 00243. 
RESUMO SIMPLES: Revisão Bibliográfica

Título: Uso de probióticos orais no tratamento e prevenção da recorrência de candidíase vulvovaginal: uma revisão sistemática

Autor/coautores: Mariana Melo de Morais; Camila Vieira Rocha de Sousa; Samuel Oliveira Dumont Horta; Michael Zarnowski Passos.

Instituição: Faculdade de Minas (FAMINAS-BH), Belo Horizonte - MG.

Palavras-chave: Treatment, Probiotics, Candidiasis.

\section{INTRODUÇÃO}

A candidíase vulvovaginal (CVV) é uma enfermidade comum, caracterizada por sinais e sintomas de inflamação vaginal como prurido, dispareunia e corrimento vaginal grumoso. Esta ocorre devido à hipeproliferação local de espécies de cândida e possui elevada taxa de recorrência mesmo após tratamento. Sendo assim, o uso de probióticos orais (PO) no tratamento adjuvante com antifúngicos azólicos (AA), reduz sintomas e a recorrência da CVV, pois possuem lactobacilos (LB) que recuperam a flora vaginal normal e assim aumentam a defesa local (ROSTOK M, et al., 2019) (RUSSO R, et al., 2019).

\section{OBJETIVO}

Revisar e analisar a eficácia e os resultados do uso de PO contendo LB na prevenção da recorrência e dos sintomas da CVV e como tratamento adjuvante dos AA.

\section{MÉTODO}

Foi realizada uma revisão sistemática por meio de ensaios clínicos randomizados, publicados há 5 anos, em inglês, com estudos em humanos, com referência à base de dados MedLine. A pesquisa pelos descritores foi realizada pelo MeSH. Inicialmente, foram encontrados 206 estudos e após aplicação dos critérios de inclusão (mulheres com CVV sintomática ou com CVV recorrente), e exclusão (pacientes com candidíase oral ou grávidas), 4 artigos fizeram parte do escopo final. A escala PRISMA foi utilizada.

\section{REVISÃO BIBLIOGRÁFICA}

A CVV possui o Fluconazol como padrão ouro de tratamento, mas $50 \%$ das pacientes possuem recidiva dos sintomas após 6 meses do tratamento. Dessa maneira, o PO Respecta®, formado por LB e lactoferrina, após o tratamento com AA, em 6 meses gerou uma taxa geral de cura no grupo Respecta ${ }^{\circledR}$ de 70,8\%, enquanto no grupo placebo não houve melhora dos sintomas. $E$, a recorrência da CVV foi de $29,2 \%$ no grupo controle e $91,7 \%$ no placebo (RUSSO R, et al., 2019). Ademais, outro estudo evidenciou que dentro de 6 meses após o tratamento com Fluconazol e uso de PO com LB, a recorrência da CVV foi de $7,2 \%$ no grupo controle e de $35,5 \%$ no placebo (DAVAR R, et al., 2016). Já, outro PO com Lactobacillus plantarum $P 17630$, em 45 dias diminuiu os sintomas no grupo controle $(p=0,002)$ e no placebo $(p=0,006)$, e em 3 meses somente no grupo controle (VLADAREANU R, et al.,2018).

\section{CONSIDERAÇÕES FINAIS}

O uso de PO com LB em sua composição são eficazes como tratamento adjuvante de AA, na redução dos sintomas e da recorrência da CVV. Porém, mais estudos são necessários para determinar o melhor tipo e a dose apropriada destes. 


\section{REFERÊNCIAS}

1. DAVAR R, et al. Comparing the recurrence of vulvovaginal candidiasis in patients undergoing prophylactic treatment with probiotic and placebo during the 6 months. Probiotics and antimicrobial proteins, 2016; 8(3), 130-133.

2. ROSTOK M, et al. Potential vaginal probiotics: safety, tolerability and preliminary effectiveness. Beneficial Microbes, 2019; 10(4), 385-393.

3. RUSSO R, et al. Randomised clinical trial in women with Recurrent Vulvovaginal Candidiasis: Efficacy of probiotics and lactoferrin as maintenance treatment. Mycoses, 2019; 62(4), 328-335.

4. VLADAREANU R, et al. New evidence on oral L. plantarum P17630 product in women with history of recurrent vulvovaginal candidiasis (RVVC): a randomized double-blind placebo-controlled study. Eur Rev Med Pharmacol Sci, 2018; 22(1), 262-267. 


\section{AGRADECIMENTOS}

\section{Patrocinadores}

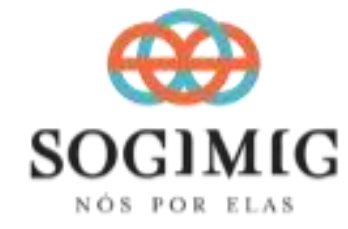

SQMUTV

$J A L E K O$

\section{sjt $>$ med}

EDUCAGĀO MEDICA
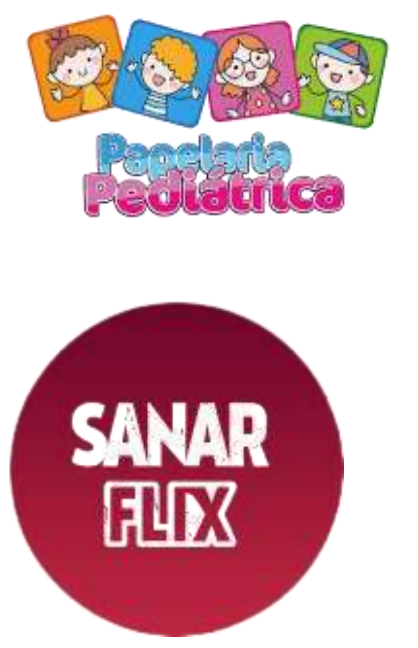

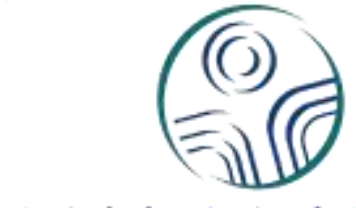

Sociedade Mineira de Pediatria

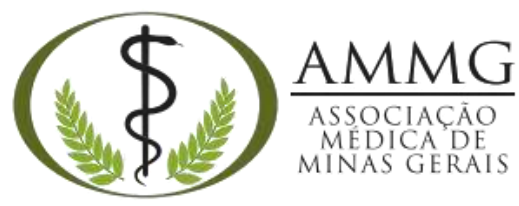

\section{SÀMMG

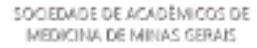

MedCapital
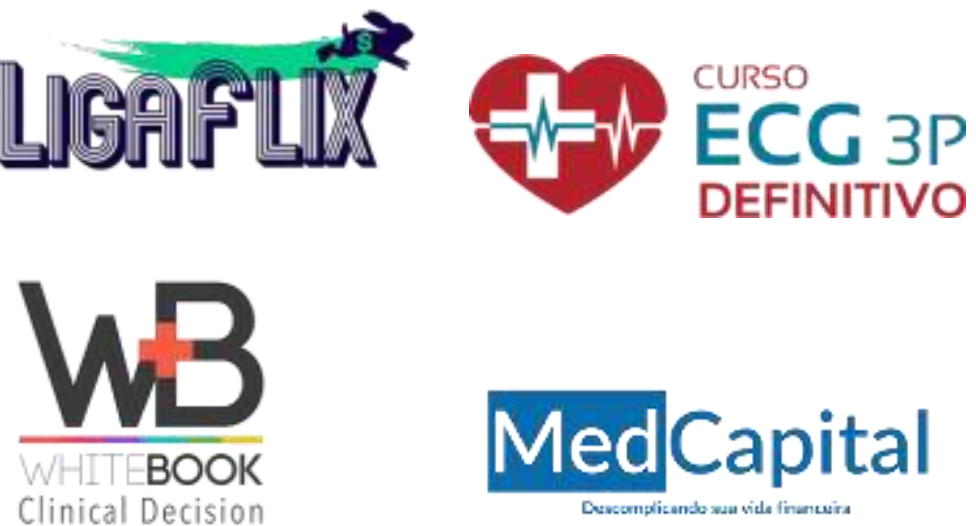

Cescomplizande sua side finumwirs

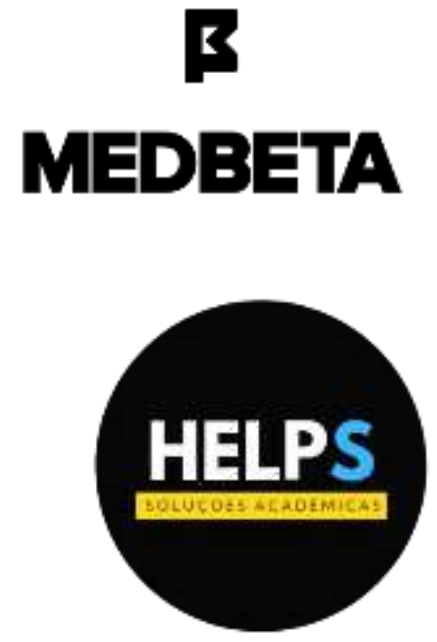

MedAULA

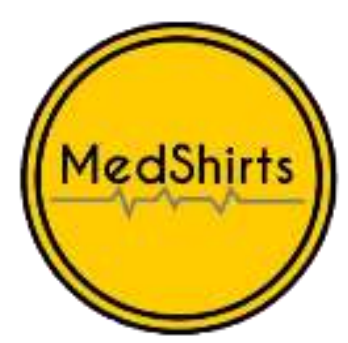

